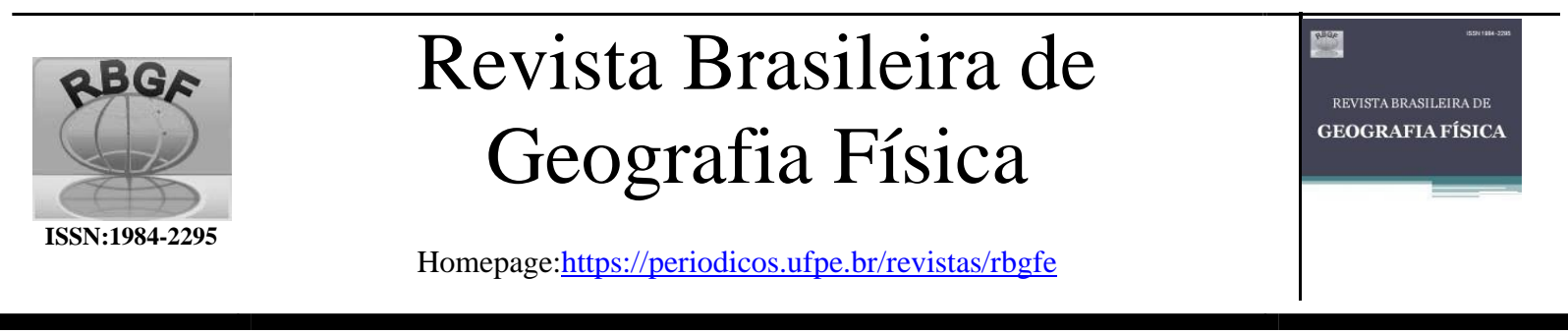

\title{
Construção de cenários futuros da temperatura máxima do ar: Capitais do Nordeste Brasileiro
}

Ana Carla dos Santos Gomes ${ }^{1}$, Maytê Duarte Leal Coutinho ${ }^{2}$, Fábio de Paula Viana ${ }^{3}$, Losany Branches ${ }^{4}$, Sivaldo Filho Seixas Tavares ${ }^{5}$, Vivianne Martins Alfaia ${ }^{6}$, Ana Vitória Padilha Mendes ${ }^{7}$, Safira Silva ${ }^{8}$, Eliane Leite Reis de Sousa ${ }^{9}$, Tiago Bentes Mandú ${ }^{10}$.

${ }^{1}$ Dra. em Ciências Climáticas, Universidade Federal do Oeste do Par, s/n, CEP 68040420, Santarém, Pará. ana.gomes@ufopa.edu.br (autor correspondente). ${ }^{2}$ Dra. Pesquisadora, Instituto Nacional de Meteorologia, Recife, Pernambuco. mayte.coutinho@inmet.gov.br, ${ }^{3}$ Graduando em Ciências Atmosféricas, Universidade Federal do Pará, Santarém, Pará. fabiodepaulaviana123@gmail.com, ${ }^{4}$ Graduanda em Ciências Atmosféricas, Universidade Federal do Pará, Santarém, Pará. lbranchesv@ gmail.com. ${ }^{5}$ Mestrando em Demografia, Universidade Federal do Rio Grande do Norte, Natal, Rio Grande do Norte. sivaldo.filho11@gmail.com, ${ }^{6}$ Mestranda em Ciências Climáticas, Universidade Federal do Rio Grande do Norte, Natal, Rio Grande do Norte. alfaiavivimartins@gmail.com, ${ }^{7}$ Graduanda em Ciências Atmosféricas, Universidade Federal do Pará, Santarém, Pará. nha_2309@hotmail.com, ${ }^{8}$ Graduanda em Ciências Atmosféricas, Universidade Federal do Pará, Santarém, Pará. safiranoronha98@gmail.com, ${ }^{9}$ Graduanda em Ciências Atmosféricas, Universidade Federal do Pará, Santarém, Pará. elianeleitestm@gmail.com, ${ }^{10}$ Mestrando em Meteorologia, Instituto Nacional de Pesquisas Espaciais, São José dos Campos, São Paulo. tiagobentes1 @ gmail.com.

Artigo recebido em 12/02/2021 e aceito em 27/06/2021

\section{R E S U M O}

Esta pesquisa busca analisar e estimar cenários futuros da temperatura máxima do ar nas capitais do Nordeste Brasileiro, com o intuito de evidenciar a importância das alterações climáticas hoje e no futuro. Para isso, utilizaram-se dados de precipitação pluvial, velocidade do vento, umidade relativa e temperatura máxima do ar, disponibilizados pelo banco de dados meteorológicos de ensino e pesquisa do Instituto Nacional de Meteorologia, das noves capitais da região nordeste do Brasil no período de 1980 a 2019, e a técnica via regressão dinâmica que combinam a dinâmica de séries temporais e o efeito de variáveis explicativas. Os principais resultados mostraram que o modelo de regressão dinâmica, ajustou de forma satisfatória a associação entre as variáveis meteorológicas. Foram consideradas as funções de tendência (sem defasagem) e de sazonalidade (com defasagem) em todas as capitais, apresentando a ocorrência de diferentes defasagens conforme a capital e a variável. De forma que, as temperaturas mais elevadas dentre as capitais analisadas ocorreram em Teresina/PI e as menos elevadas, em Salvador/BA. Em termos gerais, os cenários otimistas (C1) apresentaram temperatura entre 32,5 e $35^{\circ} \mathrm{C}$, os pessimistas (C2) entre 36 e $37,5^{\circ} \mathrm{C}$ e os extremos (C3) 35 e $39^{\circ} \mathrm{C}$, evidenciando que todos os cenários futuros apresentam perigo para a população. Espera-se que os resultados obtidos possam auxiliar políticas públicas.

Palavras-Chave: Clima, Modelagem Estocástica, Regressão Dinâmica.

\section{Construction of future scenarios of maximum air temperature: Capitals of the Brazilian Northeast}

\begin{abstract}
A B S T R A C T
This research aims to analyze and estimate future scenarios of maximum air temperature in the capitals of northeastern Brazil, in order to highlight the importance of climate change today and in the future. For this, rainfall, wind speed, relative humidity and maximum air temperature data were used by the database meteorological activities of the National Institute of Meteorology, of the nine capitals of the northeastern region of Brazil from 1980 to 2019, and the dynamic regression technique that combines the dynamics of time series and the effect of explanatory variables. The main results showed that the dynamic regression model satisfactorily adjusted the association between meteorological variables.Trend (without lag) and seasonality (lag) functions were considered in all capitals, presenting the occurrence of different lags according to the
\end{abstract}


capital and the variable. Thus, the highest temperatures among the capitals analyzed occurred in Teresina/PI and the least high, in Salvador/BA. In general terms, the optimistic scenarios (C1) presented temperature between 32.5 and $35^{\circ} \mathrm{C}$, the pessimists $(\mathrm{C} 2)$ between $37.5^{\circ} \mathrm{C}$ and extremes $(\mathrm{C} 3) 35$ and $39^{\circ} \mathrm{C}$, evidencing that all future scenarios present danger to the population. It is expected that the results obtained can help public policies.

Keywords:_Climate, Stochastic Modeling, Dynamic Regression.

\section{Introdução}

O Nordeste Brasileiro (NEB) está localizado no extremo leste da América do Sul, banhado pelo Oceano Atlântico, apresenta acentuada variabilidade interanual, principalmente no que se refere às chuvas, com alguns anos extremamente secos e outros extremamente chuvosos, o que junto com urbanização, poluição do ar e mudança do uso do solo afeta diretamente nos valores da temperatura do ar (Lacerda et al., 2015; Oliveira et al., 2016).

Alterações provocadas pela ação humana no sistema climático estão sendo observadas, e as causas mais discutidas são as mudanças nas concentrações de gases de efeito estufa (GEEs), no uso da terra, nas quantidades de aerossóis na atmosfera etc. Essas modificações têm impactos no clima, tanto regional quanto global (IPCC, 2019). No Brasil regiões como a Amazônia e o Nordeste do Brasil são consideradas vulneráveis às mudanças do clima e necessitam de mais estudos acerca das alterações climáticas naturais e antrópicas (Kayano e Andreoli, 2009; PBMC, 2014; Guimarães et al, 2016)

Os extremos de temperatura na terra têm aumentado desde 1950 e, desde então, pode-se observar que o sistema climático como um todo acumulou mais energia do que perdeu (IPCC, 2013). $\mathrm{O}$ aumento nas temperaturas médias, combinado a nova composição química da atmosfera, desencadeou alterações significativas no sistema climático planetário, afetando o padrão das chuvas, com impactos no ciclo hidrológico, produzindo enchentes intensas, secas severas e frequentes ondas de frio e calor com consequências na segurança alimentar, saúde e segurança hídrica (Lacerda et al 2015). O NEB está vulnerável aos processos de desertificação, à ocorrência de eventos extremos do clima tais como secas e enchentes e avanços do mar (Barbieri et al., 2018; Tomasella, et al., 2018). Indiretamente afeta também a saúde da população, pois causam óbitos, deixam pessoas feridas, desabrigadas, e aumentam o risco de contaminação por doenças de veiculação hídrica (Hacon et al., 2018). Outra consequência é a degradação do solo na região semiárida do NEB que é impulsionada por um conjunto de fatores, dos quais o clima, a econômica e o crescimento populacional são os mais importantes.

As secas produzem choques econômicos, que provocam a queda dos preços dos produtos, o que acaba reduzindo a atratividade da região para o trabalho agrícola (Pavani et al., 2018). Além do processo de degradação acelerado da região, os cenários de mudanças climáticas indicam que a região provavelmente será afetada por déficits de chuvas e aumento da aridez na segunda metade do século 21 (Marengo \& Bernasconi, 2015; IPCC, 2020), que terá impactos severos na produção da agricultura de sequeiro (Martins et al., 2019).

Segundo Vieira et al., (2019) os cenários para a degradação no NEB sugerem um aumento de aproximadamente $53 \%$ da área sob alta suscetibilidade à desertificação no período de 2010 a 2040. Todas as simulações indicaram que a área ocupada por vegetação natural deve ser reduzida de $237.119 \mathrm{~km}^{2}$ em 2010 para $58.714 \mathrm{~km}^{2}$ em 2040.

Segundo o "Relatório do Painel Brasileiro de Mudanças Climáticas" (PBMC, 2013), é provável que o semiárido nordestino tenha com aumento de temperatura até $1^{\circ} \mathrm{C}$. Esse relatório, também, indicou que todo o Brasil deverá ficar ao menos $3{ }^{\circ} \mathrm{C}$ mais quente até o fim do século, que as precipitações aumentarão em 30\% nas regiões Sul e Sudeste e diminuirão em até $40 \%$ nas regiões norte e nordeste.

A influência antrópica sobre o clima ressalta a fragilidade dos sistemas humanos e naturais (Silva e Colombo, 2019; ONU 2020) e influencia negativamente na capacidade adaptativa para lidar com os impactos (Cattaneo et al., 2019). Destaca-se que projeções para o clima futuro são fundamentais para estratégias de adaptação e combate à vulnerabilidade. Segundo Queiroz e Costa (2012) a variabilidade é um dos elementos mais conhecidos da dinâmica climática. $\mathrm{O}$ impacto produzido por essa variabilidade, mesmo dentro da normalidade, pode ter efeitos relevantes nas atividades humanas e as 
anomalias podem desestruturar tanto o sistema ambiental quanto o socioeconômico.

Segundo o relatório da United Nations Disaster Risk Reduction (UNDRR, 2019), mais de $50 \%$ da população mundial vive em áreas urbanas, até 2050 esse percentual deve aumentar para 75\%, e é exatamente nas cidades que se concentram as populações mais afetadas por eventos extremos de clima.

A variabilidade climática não é dependente somente da complexa dinâmica atmosférica, mas também de influências externas ao planeta como as mudanças solares, embora sejam as escalas a nível local e regional que sentirão os maiores impactos climáticos (Queiroz e Costa, 2012). Torres et al., (2015) constaram tendência de aumento da temperatura máxima com significância estatística em 90 estações todos estados do nordeste brasileiro, sendo que, as maiores foram nas estações dos estados do Maranhão e Piauí.

Em um contexto mundial e ao considerar a nova realidade que o ser humano passou a enfrentar com o surgimento da pandemia, levanta-se a hipótese que ao conhecer cenários futuros das mudanças do clima cada vez mais específico possibilitará o enfrentamento de suas consequências. Béné (2020) e Bayer et al., (2021) sinalizam que as mudanças na diversidade global de morcegos sugerem um possível papel das mudanças climáticas no surgimento de SARS-CoV-1 e SARS-CoV-2, o que evidencia a relevância deste tipo de trabalho, diante o mencionado objetiva-se analisar e estimar cenários futuros da temperatura máxima do ar nas capitais do NEB, com auxílio da modelagem estocástica via regressão dinâmica.

\section{Material e métodos}

\section{Região de estudo}

A área de estudo abrange todas as capitais nordestinas: Recife (PE), Teresina (PI), Natal (RN), Aracaju (SE), Fortaleza (CE), João Pessoa (PB), Maceió (AL), São Luís (MA) e Salvador (BA). O NEB apresenta o maior número de estados do Brasil e tem a segunda maior população, devido à sua grande extensão e localização, o NEB sofre a influência de vários sistemas atmosféricos, dentre os quais se destacam a zona de convergência intertropical, ondas de leste, frentes frias, brisas e vórtices ciclônicos de ar superior (Roucou et al., 1996). Essa região se caracteriza pelos baixos níveis pluviais, temperaturas elevadas e altas taxas de evaporação. A alta demanda atmosférica produz taxas de evaporação que podem superar até $10 \mathrm{~mm}$ por dia, enquanto a temperatura média do ar varia entre 16,8 a $33,8^{\circ} \mathrm{C}$.

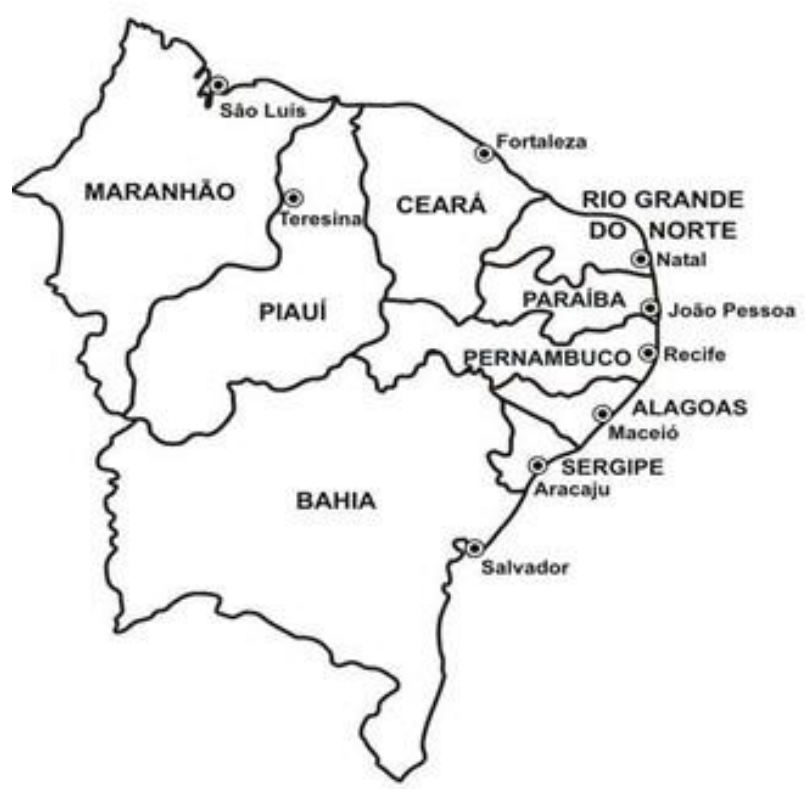

Figura 1. Mapa de localização das capitais do Nordeste Brasileiro. 


\section{Dados Observados}

Neste trabalho foram utilizados os dados meteorológicos mensais, entre os anos de 1980 a 2019 disponibilizados pelo Banco de Dados de Ensino e Pesquisa (BDMEP) do Instituto Nacional de Meteorologia (INMET). As falhas foram preenchidas por meio da imputação múltipla via Multivariate Imputation by Chained Equations (MICE) para preencher estes registros faltantes. O MICE é uma metodologia estatística baseada no amostrador de Gibbs, uma técnica de simulação Bayesiana onde as distribuições condicionais dos dados são utilizadas para obter amostras de distribuição conjunta a fim de gerar múltiplas imputações para inferir dados onde anteriormente haviam falhas (Van Buuren e Groothuis-Oudshoorn, 2011) A escolha desta metodologia é baseada no desempenho satisfatório que o MICE Apresentou na imputação de registros meteorológicos, observada em estudos anteriores como o de Alves e Gomes (2020) e Mandú et al (2020).

Dentre as técnicas de imputação disponíveis no MICE, optou-se pelo método da Média Preditiva Correspondente (MPC). De acordo com Li et al. (1991) é uma alternativa do modelo de regressão linear, que determina um valor a partir do modelo de regressão mais próximo do valor observado, utilizando os registros existentes. Vink et al. (2014) assinalam que a MPC é uma abordagem estatística robusta, uma vez que combina elementos da regressão linear, reduzindo assim a variabilidade e melhora as estimativas. O cálculo da MPC para cada dado faltante $i$ em $Y$ pode ser obtido a partir da equação 1 contida em Lopo et al. (2014).

$$
\hat{Y}^{\mathrm{obs}}=\left\{\mathrm{Y}_{\mathrm{i}}^{\mathrm{obs}}=\mathrm{X}_{\mathrm{i}}^{\prime} \beta^{*} ; \mathrm{i} \in \mathrm{obs}(\mathrm{Y})\right\}(1)
$$

Onde X é a variável sem ausência de dados, $\hat{Y}^{\text {obs }} \mathrm{o}$ grupo de valores observados, e $Y_{i}{ }^{\text {obs }}=X_{i}^{\prime} \beta^{*}$ que obtém $Y_{i}{ }^{\text {obs }}$ como observação mais próxima.

Para a construção dos modelos foram utilizadas as seguintes variáveis climáticas: temperatura máxima do ar $\left({ }^{\circ} \mathrm{C}\right)$ como variável dependente, precipitação pluvial $(\mathrm{mm})$, umidade relativa do ar $(\%)$ e velocidade do vento $(\mathrm{m} / \mathrm{s})$ como variáveis independentes.

\section{Metodologia}

A estatística descritiva é a etapa inicial da análise utilizada para descrever e resumir os dados.
Utilizaram-se os gráficos boxplot, além do cálculo de medidas de posição, dispersão e de associação. Com a finalidade de averiguar o ajuste entre as variáveis meteorológicas e o poder preditivo da modelagem estocástica, utilizou-se a regressão dinâmica.

Os Modelos de Regressão Dinâmica (MRD) combinam a dinâmica de séries temporais e o efeito de variáveis explicativas. Trata-se de um modelo matemático de regressão envolvendo séries de tempo, que inclui não somente valores atuais da variável em estudo, como também os valores históricos (Pankratz, 1991). Além disso, é possível incluir as variáveis independentes da variável dependente ao modelo com ou sem defasagens (lag) das variáveis. Portanto, no MRD, a variável dependente é explicada por seus valores defasados e pelos valores atuais e passados de variáveis explicativas. Então, considerando os valores defasados da variável $\left(Y_{t-1}\right)$ e de suas preditoras $\left(X_{n, t}\right)$ ou preditoras defasadas $\left(X_{n, t-k}\right)$ utiliza-se a seguinte equação dinâmica:

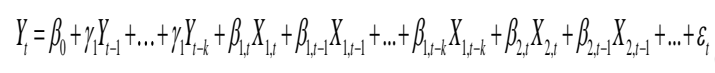

sendo os índices $t-i$ as variáveis e parâmetros com $i$ defasagens. $\mathrm{Na}$ equação acrescenta-se um termo estocástico $\left(\varepsilon_{t}\right)$, assim como algumas flutuações normalmente distribuídas e insignificantes para o modelo (Pankratz, 1991).

É importante mencionar que será considerado o melhor ajuste à distribuição da temperatura máxima do ar, quando associação for estatisticamente significativa ( $p<0,00001)$. A escala utilizada será mensal, o atraso observado por meio da defasagem, obedece a essa escala, e o lag 0 significa que a variável foi utilizada de forma direta, sem defasagem.

Para estimação dos parâmetros, utilizamos o método dos Mínimos Quadrados Ordinários, desde que o termo estocástico $\left(\varepsilon_{t}\right)$ tenha as propriedades adequadas como média zero $\left(\mathrm{E}\left(\varepsilon_{t}\right)=0\right)$, homoscedasticidade $\left(\operatorname{Var}\left(\varepsilon_{t}\right)=\sigma^{2}\right)$ e erros não correlacionados $\left(\mathrm{E}\left(\varepsilon_{i}, \varepsilon_{j}\right)=0\right.$, se $\left.\mathrm{i}>\mathrm{j}\right)$.

A hipótese básica para que se faça uma previsão adequada, utilizando-se a regressão dinâmica, é que o padrão de comportamento da série deve ser representado pela defasagem de observações passadas. Assim, uma grande classe de formas funcionais, tais como uma constante, uma tendência linear, um padrão sazonal ou qualquer 
forma polinomial pode ser previsto utilizando-se esta técnica (Morettin e Toloi 1985; Box et al., 2008, Gomes et al., 2018).

A construção dos cenários futuros, ocorrerá com base em projeções de mudanças climáticas segundo o relatório do Painel intergovernamental de mudanças climáticas (IPCC, 2019) a partir das previsões do MRD, por meio do aumento da temperatura máxima do ar conforme os períodos e classificações na Tabela 1.

Tabela 1: Composição dos cenários de aumento da temperatura máxima do ar nas Capitais do Nordeste Brasileiro.

\begin{tabular}{ccc}
\hline Projeções & $\begin{array}{c}\text { Temperatura } \\
\text { máxima do ar }\left({ }^{\circ} \mathbf{C}\right)\end{array}$ & Classificação \\
\hline $\begin{array}{c}\text { Cenário } 1 \\
(\mathrm{C} 1)\end{array}$ & $+2,5$ & Otimista \\
$\begin{array}{c}\text { Cenário } 2 \\
(\mathrm{C} 2)\end{array}$ & $+4,0$ & Pessimista \\
$\begin{array}{c}\text { Cenário } 3 \\
\text { (C3) }\end{array}$ & $+5,0$ & Extremo \\
\end{tabular}

Todas as técnicas estatísticas mencionadas foram implementadas com o auxílio do software estatístico livre R 4.0. (R, 2020).

\section{Resultados e discussão}

A temperatura máxima do ar (tmáx) nas capitais do NEB são diferentes devido suas localizações geográficas, influência de diferentes sistemas meteorológicos e pela urbanização, o que justifica as diferenças visualizadas na Tabela 2, por meio da estatística descritiva. Destaca-se que no período analisado, Teresina apresenta os maiores valores, caracterizando-se como a Capital mais quente da região. Fortaleza é a capital com menor variabilidade e menor amplitude. Enquanto Salvador, apresenta menor valor da tmáx durante o período estudado.

Tabela 2. Estatísticas descritivas da temperatura máxima do ar $\left({ }^{\circ} \mathrm{C}\right)$ das capitais do Nordeste no período de 1980 a 2019.

\begin{tabular}{c|cccccccccc}
\hline Estatísticas & São Luís & \multicolumn{1}{|c}{ Teresina Fortaleza Natal } & Recife João Pessoa & Maceió & \multicolumn{3}{c}{ Aracaju Salvador } \\
\hline Mínima & 28,39 & 30,51 & 28,81 & 27,57 & 26,98 & 27,36 & 26,8 & 26,75 & $\mathbf{2 5 , 5 4}$ \\
& 31,32 & $\mathbf{3 4 , 0 9}$ & 30,88 & 29,81 & 29,68 & 29,98 & 29,87 & 29,6 & 28,9 \\
\hline Mediana & & & & & & & & & \\
\hline Média & 31,27 & $\mathbf{3 4 , 1 8}$ & 30,89 & 29,69 & 29,58 & 29,92 & 29,83 & 29,53 & 28,88 \\
\hline Máxima & 33,89 & $\mathbf{3 9 , 0 3}$ & 32,59 & 32,54 & 32,58 & 32,46 & 32,69 & 32,65 & 33,18 \\
\hline Amplitude & 5,5 & $\mathbf{8 , 5 2}$ & $\mathbf{3 , 7 8}$ & 4,97 & 5,6 & 5,1 & 5,89 & 5,9 & 7,64 \\
\hline
\end{tabular}

As Figuras 2, 3 e 4 mostram a variação temporal da tmáx anual e mensal das capitais do NEB. De maneira geral, percebe-se mudanças na sua variabilidade concentrada no início da década de 2000. As séries de São Luiz e Teresina (Figuras 2a,2b), João Pessoa e Recife (Figuras 3a, 3b) são 
bons exemplos deste comportamento. É possível observar essa mudança no padrão das médias da tmáx, em que se apresentam superiores à média geral (pontos vermelhos). Com respeito a Maceió, Aracaju e Salvador, a mudança é mais sútil conforme mostra a (Figuras 4a, 4b, 4c).

Molion (2005) explica que parte do aquecimento observado nas recentes décadas, pode ter sido decorrente da grande contribuição à mudança das anomalias de negativas para positivas do oceano Pacífico em meados da década de 1970, sugerindo a influência de fenômenos de escala planetária como o El Niño Oscilação Sul (ENOS) e a Oscilação Decadal do Pacífico (Pacific Dezadal Oscillation $P D O)$. Este autor ressalta que a frequência de El Niño de forte intensidade foi maior entre 1977 e 1998, o que sugere maior aquecimento nos períodos recentes.
Ainda sobre a variabilidade anual, percebese que nos períodos 1982-1983 e em 1997-1998 em praticamente todas as capitais, houve elevação da tmáx devido ocorrência de forte El Niño (Smith e Reynolds, 2003). Em Natal (Figura 3a), Maceió e Aracaju (Figuras 4a, 4b) a tmáx praticamente se manteve na média. Em contrapartida, o decréscimo da tmáx em 2008 e 2011, principalmente em Recife (Figura 3c), Maceió e Salvador (Figuras 4a, 4c) atingiram a mínima da Tmáx em torno de $27^{\circ} \mathrm{C}$, devido a atuação de uma La Niña moderada (CPTEC, 2020). No contexto geral, estes resultados são coerentes aos obtidos por outros estudos (Molion \& Bernardo, 2002; Molion, 2005) que apontam nestes períodos mudanças na variabilidade da temperatura do ar.
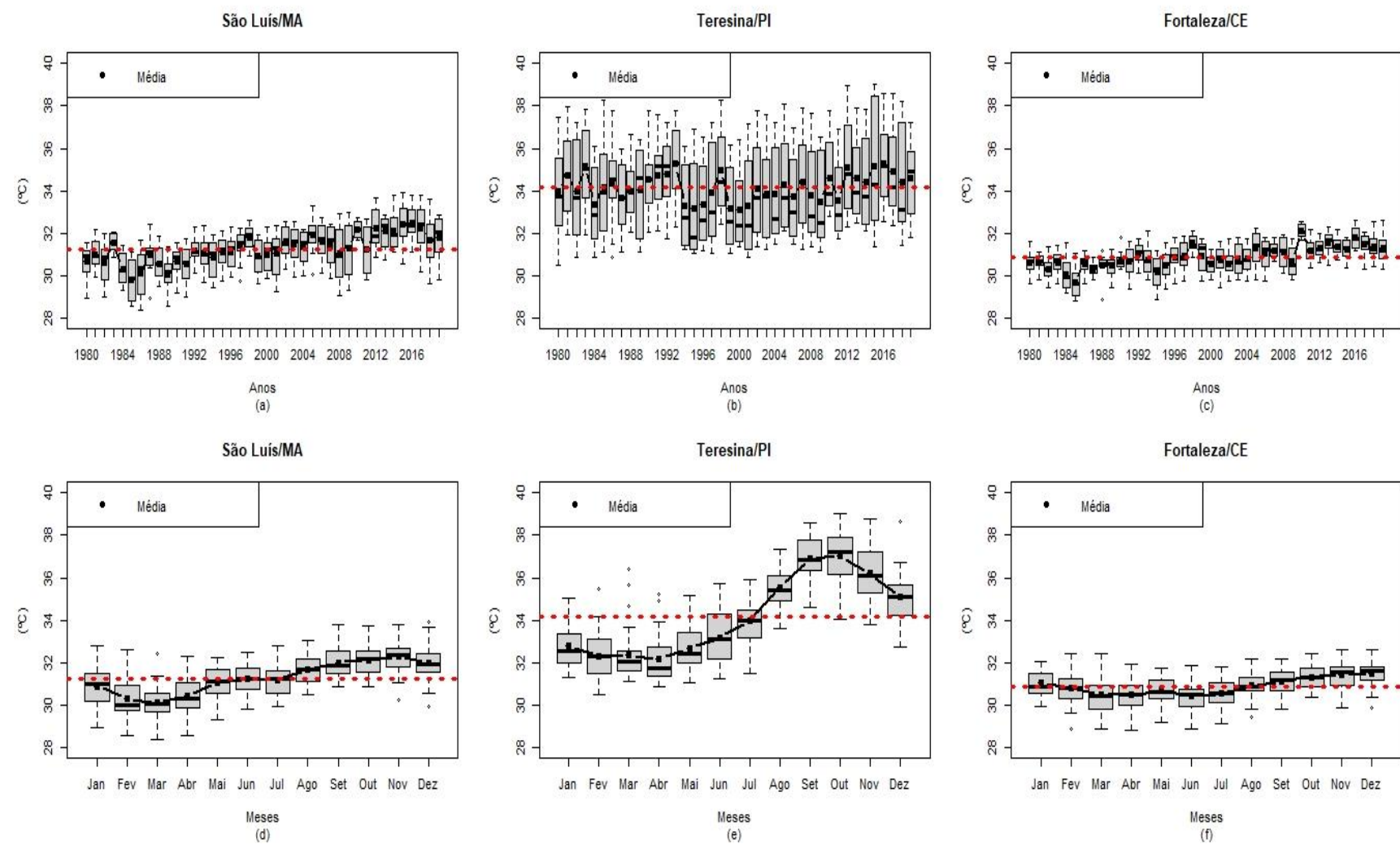

Figura 2. Variabilidade temporal da Temperatura máxima do ar $\left({ }^{\circ} \mathrm{C}\right)$ anual e mensal das seguintes capitais: São Luiz/MA (a, d), Teresina/PI (b, e) e Fortaleza/CE (c, f) no período de estudo.

Verifica-se que de certa forma, as capitais nordestinas têm semelhanças em sua variabilidade temporal. Na Figura 2, por exemplo, a máxima da tmáx de São Luiz e Fortaleza (Figuras 2a, 2c) não 
Revista Brasileira de Geografia Física v.14, n.04 (2021) 2427-2445.

excede $34^{\circ} \mathrm{C}$ na série analisada e, a média geral das duas capitais ficam em torno de $31^{\circ} \mathrm{C}$ como observado anteriormente (Tabela 2). No entanto, Teresina (Figura 2b) difere de todas as outras capitais, pois se encontra mais afastada do oceano, com a máxima da tmáx em torno de $39^{\circ} \mathrm{C}$ (Tabela 2).

Com relação a variabilidade temporal mensal, observa-se que a tmáx apresenta um decréscimo no período de fevereiro a maio (Figuras $2 \mathrm{~d}, 2 \mathrm{e}, 2 \mathrm{f}$ ) exatamente no período chuvoso da região norte do NEB atingindo as capitais do Maranhão, Teresina e Fortaleza. O principal sistema gerador de precipitação nesta região é a proximidade da Zona de Convergência Intertropical (ZCIT) (Uvo, 1989; Wang, 2002; Ferreira e Mello, 2005). Em contrapartida, um aumento considerável da tmáx (Figuras 2d, e, f) ocorre entre agosto e novembro, considerado estação seca (Marengo, 2008) no norte do NEB.

Padrão semelhante é observado entre as seguintes capitais: Natal, João Pessoa e Recife
(Figura 3). As suas tmáx variam entre 27 e $33^{\circ} \mathrm{C}$, são capitais vizinhas $\mathrm{e}$, que apresentam um decréscimo na tmáx no período de junho a agosto (Figura 3e, f), que coincide com o período chuvoso no leste do NEB. Nesta época do ano, os distúrbios ondulatórios de leste (DOL) são os responsáveis pela formação de aglomerados de nuvens que causam chuvas nesta região (Ferreira e Mello, 2005; Coutinho e Fish, 2007; Correa et al., 2019). Mas também é inverno no Hemisfério Sul que, em geral, há queda nas temperaturas pela maior frequência de sistemas frontais de maio a setembro (Cavalcanti e Kousky 2003; Andrade 2005), que se aproximam pelo sul do NEB e, acabam de certa forma, influenciando a região de forma indireta (Figuras 3e, 3f). Nota-se ainda, que Natal (Figura 3a) antecipa um pouco o decaimento da tmáx (março a junho), pois esta capital pode ser favorecida também pela atuação da ZCIT, como comentado anteriormente. No que diz respeito ao aumento da tmáx, verifica-se entre agosto e novembro sugerindo estação seca (Marengo, 2008) no leste do NEB (Figuras 3d, 3e, 3f).
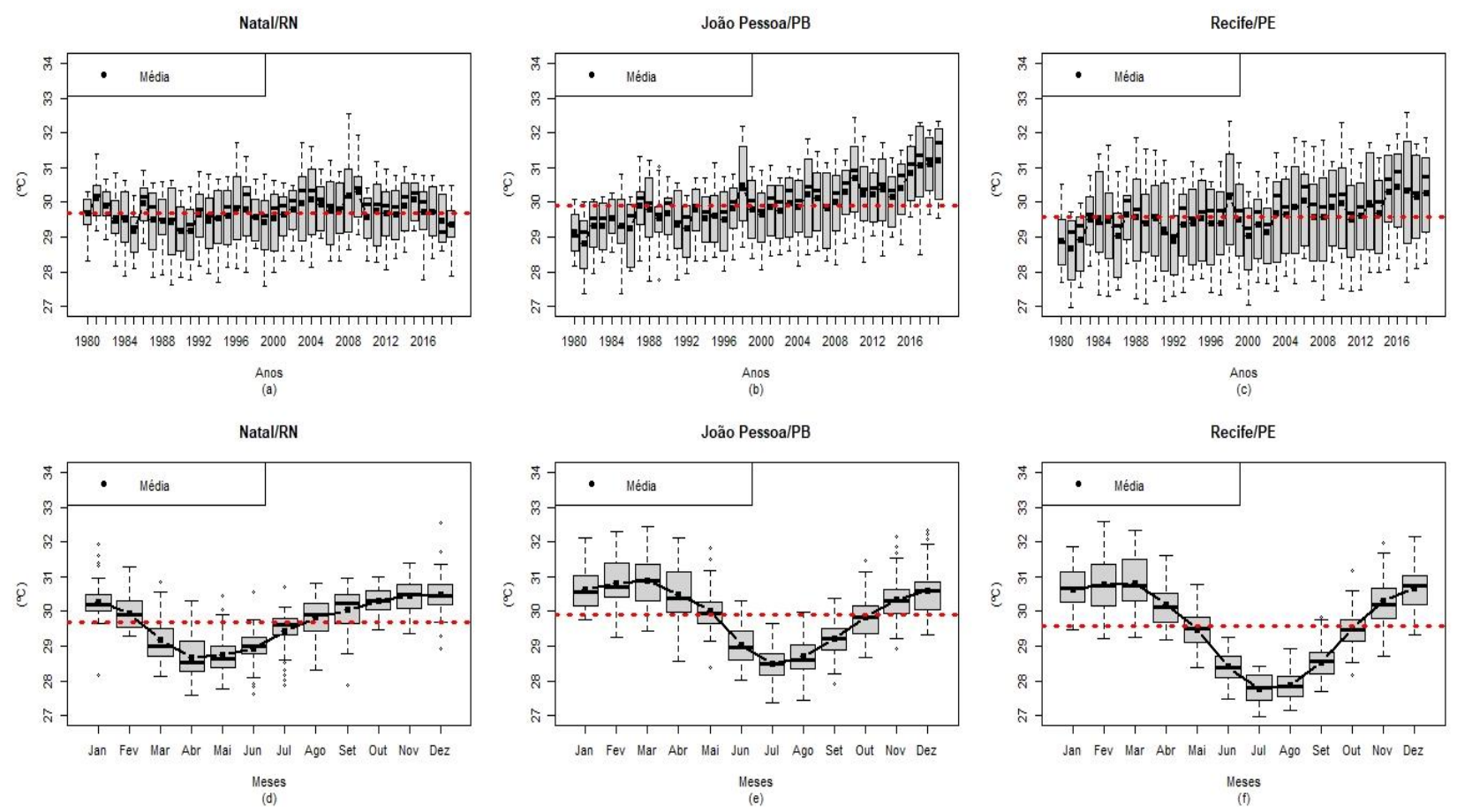

Figura 3. Variabilidade temporal da Temperatura máxima do ar $\left({ }^{\circ} \mathrm{C}\right)$ anual e mensal das seguintes capitais: Natal/RN (a, d), João Pessoa/PB (b, e) e Recife/PE (c, f) no período de estudo. 
Revista Brasileira de Geografia Física v.14, n.04 (2021) 2427-2445.

Resultado similar é observado nas capitais de Maceió e Aracaju (Figuras 4d, 4e) quando comparado a (Figuras 3d, 3e, 3f). Porém, o caimento da tmáx em Maceió (Figura 4d) inicia em março e segue até agosto e, em Aracaju de fevereiro a julho (Figura 4e). Já Salvador (Figura $4 \mathrm{e})$, possui a mínima da tmáx de todas as capitais, com valor de $25,5^{\circ} \mathrm{C}$ e sua máxima não excede os $33^{\circ} \mathrm{C}$ na série analisada (Tabela 2 ). $\mathrm{O}$ decaimento da tmáx nesta capital acontece nos meses de abril a agosto (Figura 4f), coincidente com os meses de incursão de sistemas frontais pelo sul do NEB (Kousky, 1979).

Com as passagens de frentes frias, este sistema faz com que as temperaturas caiam durante sua passagem (Cavalcanti e Kousky 2003; Andrade 2005). Por outro lado, o aumento da tmáx (Figura 4f) ocorre em janeiro-fevereiro-março (JFM), considerado o trimestre mais seco, justamente no período de maior acumulação de chuvas logo ao sul desta região (Marengo, 2008).
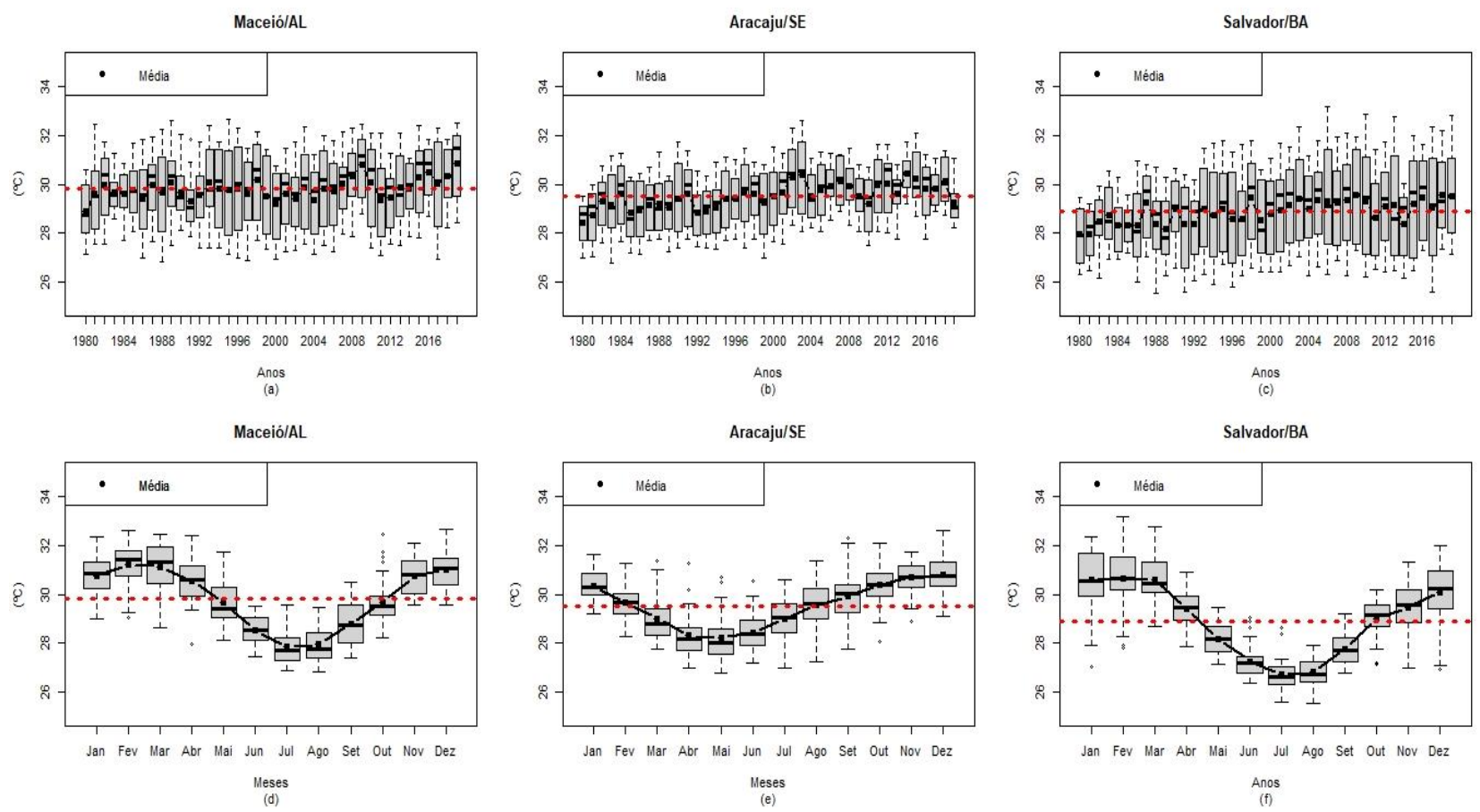

Figura 4. Variabilidade temporal da Temperatura máxima do ar $\left({ }^{\circ} \mathrm{C}\right)$ anual e mensal das seguintes capitais: Maceió/AL (a, d), Aracaju/SE (b, e) e Salvador/BA (c, f) no período de estudo.

O modelo de regressão dinâmica (MRD) ajusta satisfatoriamente a relação existente entre as variáveis meteorológicas (Tabelas 3, 4 e 5), tendo em vista que os resultados são estatisticamente significativos $(\mathrm{p}<0,00001)$. Como consequência, possibilita prever a temperatura máxima do ar a partir das demais variáveis meteorológicas.

Observa-se ainda, que as funções de tendência (sem defasagem) e da sazonalidade (com defasagem) em todas as capitais foram utilizadas na modelagem, com a ocorrência de diferentes defasagens (lag) conforme a capital e determinada variável. Yevjevich (1972) define tendência em uma série temporal como uma mudança sistemática e contínua em qualquer parâmetro de uma dada amostra, excluindo-se mudanças periódicas ou quase periódicas. A sazonalidade de um evento representa que este costuma ocorrer sempre num momento temporal específico. As variações sazonais devem ser consideradas para que as variações naturais não sejam confundidas com as alterações induzidas pela ação antrópica (PBMC, 2013).

Na Tabela 3a, observa-se o MRD que melhor se ajustou à distribuição da temperatura máxima do ar em São Luís/MA ocorreu quando levou-se em consideração a tendência, com defasagem de 1 mês, tanto na sazonalidade como 
Revista Brasileira de Geografia Física v.14, n.04 (2021) 2427-2445.

com a precipitação e a umidade relativa do ar, e no lag 0 (sem defasagem) para a velocidade do vento, com significância estatística (valor-p<0,001). Teresina/PI (Tabela 3b) e em Fortaleza/CE (Tabela 3c) o ajuste foi semelhante ao de São Luís, exceto que a tendência não apresentou significância estatística (valor- $\mathrm{p}=0,1)$ e a velocidade do vento que ajustou no lag $5 \mathrm{em}$ Teresina. Todos os três modelos apresentaram $R^{2}=0,99$ (valor-p $<0,001$ ).

Tabela 3. Coeficientes estimados do MRD para temperatura máxima do ar via variáveis meteorológicas em São Luís/MA (a), Teresina/PI (b) e Fortaleza/CE (c).

\begin{tabular}{|c|c|c|c|c|}
\hline \multicolumn{5}{|l|}{ São Luís (SL)/MA (a) } \\
\hline Variáveis & $\begin{array}{c}\text { Coeficientes } \\
\text { Estimados }\end{array}$ & Erro Padrão & Estatística T & Valor-p \\
\hline Tendência(T_SL) & 0,039 & 0,002 & 18,98 & $<2 \mathrm{e}-16 * * *$ \\
\hline Sazonalidade(T_SL, 1)Jan & 30,675 & 0,787 & 38,96 & $<2 \mathrm{e}-16 * * *$ \\
\hline Sazonalidade(T_SL, 1)Fev & 30,802 & 0,799 & 38,56 & $<2 \mathrm{e}-16 * * *$ \\
\hline Sazonalidade(T_SL, 1)Mar & 30,871 & 0,801 & 38,55 & $<2 \mathrm{e}-16 * * *$ \\
\hline Sazonalidade(T_SL, 1)Abr & 31,067 & 0,805 & 38,58 & $<2 \mathrm{e}-16 * * *$ \\
\hline Sazonalidade(T_SL, 1)Mai & 31,144 & 0,820 & 37,98 & $<2 \mathrm{e}-16 * * *$ \\
\hline Sazonalidade(T_SL, 1)Jun & 30,527 & 0,822 & 37,15 & $<2 \mathrm{e}-16 * * *$ \\
\hline Sazonalidade(T_SL, 1)Jul & 30,328 & 0,824 & 36,8 & $<2 \mathrm{e}-16 * * *$ \\
\hline Sazonalidade(T_SL, 1)Ago & 30,213 & 0,828 & 36,49 & $<2 \mathrm{e}-16 * * *$ \\
\hline Sazonalidade(T_SL, 1)Set & 30,180 & 0,803 & 37,58 & $<2 \mathrm{e}-16 * * *$ \\
\hline Sazonalidade(T_SL, 1)Out & 30,328 & 0,795 & 38,13 & $<2 \mathrm{e}-16 * * *$ \\
\hline Sazonalidade(T_SL, 1)Nov & 30,498 & 0,791 & 38,54 & $<2 \mathrm{e}-16 * * *$ \\
\hline Sazonalidade(T_SL, 1)Dez & 30,753 & 0,790 & 38,93 & $<2 \mathrm{e}-16 * * *$ \\
\hline L(Precipitação_SL, 1) & $-0,001$ & 0,000 & $-3,45$ & $0,00061 * * *$ \\
\hline L(Umidade relativa_SL, 1) & $-0,027$ & 0,010 & $-2,59$ & $0,00986 * *$ \\
\hline L(Vel. do vento_SL, 0) & 0,568 & 0,057 & 9,11 & $<2 \mathrm{e}-16 * * *$ \\
\hline \multicolumn{5}{|l|}{ Teresina $(\mathbf{T}) / \mathrm{PI}(\mathbf{b})$} \\
\hline Tendência(T_T) & 0,008 & 0,005 & 1,63 & 0,1 \\
\hline Sazonalidade(T_T, 1)Jan & 37,105 & 0,696 & 53,28 & $<2 \mathrm{e}-16 * * *$ \\
\hline Sazonalidade(T_T, 1)Fev & 37,407 & 0,758 & 49,34 & $<2 \mathrm{e}-16 * * *$ \\
\hline Sazonalidade(T_T, 1)Mar & 37,508 & 0,771 & 48,67 & $<2 \mathrm{e}-16 * * *$ \\
\hline Sazonalidade(T_T, 1)Abr & 37,441 & 0,774 & 48,39 & $<2 \mathrm{e}-16 * * *$ \\
\hline Sazonalidade(T_T, 1)Mai & 37,885 & 0,763 & 49,66 & $<2 \mathrm{e}-16 * * *$ \\
\hline Sazonalidade(T_T, 1)Jun & 37,926 & 0,741 & 51,19 & $<2 \mathrm{e}-16 * * *$ \\
\hline Sazonalidade(T_T, 1)Jul & 38,158 & 0,693 & 55,07 & $<2 \mathrm{e}-16 * * *$ \\
\hline Sazonalidade(T_T, 1)Ago & 39,408 & 0,646 & 60,96 & $<2 \mathrm{e}-16 * * *$ \\
\hline Sazonalidade(T_T, 1)Set & 40,425 & 0,604 & 66,95 & $<2 \mathrm{e}-16 * * *$ \\
\hline Sazonalidade(T_T, 1)Out & 40,369 & 0,576 & 70,11 & $<2 \mathrm{e}-16 * * *$ \\
\hline Sazonalidade(T_T, 1)Nov & 39,690 & 0,600 & 66,12 & $<2 \mathrm{e}-16 * * *$ \\
\hline Sazonalidade(T_T, 1)Dez & 38,895 & 0,644 & 60,44 & $<2 \mathrm{e}-16 * * *$ \\
\hline L(Precipitação_T, 1$)$ & $-0,002$ & 0,001 & $-3,7$ & $0,00165 * *$ \\
\hline L(Umidade relativa_T, 1 ) & $-0,052$ & 0,008 & $-6,12$ & $2,04 \mathrm{e}-09 * * *$ \\
\hline L(Vel. Do vento_T, 5) & $-0,428$ & 0,165 & $-2,59$ & $0,00994 * *$ \\
\hline \multicolumn{5}{|l|}{ Fortaleza (F)/CE(c) } \\
\hline Tendência(T_F) & 0,039 & 0,002 & 18,98 & $<2 \mathrm{e}-16 * * *$ \\
\hline Sazonalidade(T_F, 1)Jan & 30,675 & 0,787 & 38,96 & $<2 \mathrm{e}-16 * * *$ \\
\hline Sazonalidade(T_F, 1)Fev & 30,802 & 0,799 & 38,56 & $<2 \mathrm{e}-16 * * *$ \\
\hline Sazonalidade(T_F, 1)Mar & 30,871 & 0,801 & 38,5 & $<2 \mathrm{e}-16 * * *$ \\
\hline Sazonalidade(T_F, 1)Abr & 31,067 & 0,805 & 38,58 & $<2 \mathrm{e}-16 * * *$ \\
\hline
\end{tabular}

Gomes, A. C. S; Coutinho M. D. L; Viana, F. P.; Branches, L.; Tavares, S. F. S.; Alfaia, V. M.; Mendes, A. V. P.; Silva, S.; Sousa, E. L.R.; Mandú, T. B. 
Revista Brasileira de Geografia Física v.14, n.04 (2021) 2427-2445.

\begin{tabular}{|c|c|c|c|c|}
\hline Sazonalidade(T_F, 1)Mai & 31,144 & 0,820 & 37,98 & $<2 \mathrm{e}-16 * * *$ \\
\hline Sazonalidade(T_F, 1)Jun & 30,527 & 0,822 & 37,15 & $<2 \mathrm{e}-16 * * *$ \\
\hline Sazonalidade(T_F, 1)Jul & 30,328 & 0,824 & 36,8 & $<2 \mathrm{e}-16 * * *$ \\
\hline Sazonalidade(T_F, 1)Ago & 30,213 & 0,828 & 36,49 & $<2 \mathrm{e}-16 * * *$ \\
\hline Sazonalidade(T_F, 1)Set & 30,180 & 0,803 & 37,58 & $<2 \mathrm{e}-16 * * *$ \\
\hline Sazonalidade(T_F, 1)Out & 30,328 & 0,795 & 38,13 & $<2 \mathrm{e}-16 * * *$ \\
\hline Sazonalidade(T_F, 1)Nov & 30,498 & 0,791 & 38,54 & $<2 \mathrm{e}-16 * * *$ \\
\hline Sazonalidade(T_F, 1)Dez & 30,753 & 0,790 & 38,93 & $<2 \mathrm{e}-16 * * *$ \\
\hline L(Precipitação_F, 1) & $-0,001$ & 0,000 & $-3,1$ & $0,00204 * *$ \\
\hline L(Umidade relativa_F, 1 ) & $-0,027$ & 0,010 & $-2,83$ & $0,00480 * *$ \\
\hline $\mathrm{L}\left(\mathrm{V} \_\mathrm{F}, 0\right)$ & 0,568 & 0,057 & 10,03 & $<2 \mathrm{e}-16 * * *$ \\
\hline
\end{tabular}

Na Tabela 4a, observa-se que melhor se ajustou à distribuição da temperatura máxima do ar em Natal/RN ocorreu quanto com lag 1, tanto na sazonalidade como com a precipitação e a velocidade do vento, e no lag 0 (sem defasagem) para a umidade relativa do ar. Em João Pessoa/ $P B$ (Tabela 4b), lag 1 na sazonalidade e a velocidade do vento, e no lag 0 para a precipitação e a umidade relativa do ar. Já em Recife/PE destaca-se que o melhor ajuste ocorreu com a sazonalidade no lag 2 e no lag 4 da velocidade do vento sem significância estatística (valor-p=0,34). Destaca-se que a função de tendência em Natal/RN não apresentou significância estatística (valor- $\mathrm{p}=0,11$ ). Todos os três modelos apresentaram $\mathrm{R}^{2}=0,98$ (valor$\mathrm{p}<0,001)$.

Tabela 4. Coeficientes estimados do MRD para temperatura máxima do ar via variáveis meteorológicas em Natal/RN (a), João Pessoa/PB (b) e Recife/PE (c).

\begin{tabular}{|c|c|c|c|c|}
\hline \multicolumn{5}{|l|}{ Natal (N)/RN(a) } \\
\hline Variáveis & $\begin{array}{c}\text { Coeficientes } \\
\text { Estimados }\end{array}$ & Erro Padrão & Estatística T & Valor-p \\
\hline$\overline{\text { Tendência(T_N) }}$ & 0,0037 & 0,0023 & 1,59 & 0,11 \\
\hline Sazonalidade $(\mathrm{T}$ N_, 1)Jan & 32,9493 & 0,6199 & 53,15 & $<2 \mathrm{e}-16 * * *$ \\
\hline Sazonalidade( $\left.\mathrm{T}^{-} \mathrm{N}, 1\right) \mathrm{Fev}$ & 32,7139 & 0,6213 & 52,66 & $<2 \mathrm{e}-16 * * *$ \\
\hline Sazonalidade(T_N, 1)Mar & 32,0061 & 0,6248 & 51,23 & $<2 \mathrm{e}-16 * * *$ \\
\hline Sazonalidade $\left(\mathrm{T}^{-} \mathrm{N}, 1\right) \mathrm{Abr}$ & 31,7831 & 0,6382 & 49,8 & $<2 \mathrm{e}-16 * * *$ \\
\hline Sazonalidade(T_N, 1)Mai & 31,7796 & 0,6423 & 49,48 & $<2 \mathrm{e}-16 * * *$ \\
\hline Sazonalidade( $\left.\mathrm{T}^{-} \mathrm{N}, 1\right) \mathrm{Jun}$ & 31,8200 & 0,6612 & 48,13 & $<2 \mathrm{e}-16 * * *$ \\
\hline Sazonalidade(T_N, 1)Jul & 32,2032 & 0,6542 & 49,22 & $<2 \mathrm{e}-16 * * *$ \\
\hline Sazonalidade( $\left.\mathrm{T}^{-} \mathrm{N}, 1\right)$ Ago & 32,4450 & 0,6400 & 50,7 & $<2 \mathrm{e}-16 * * *$ \\
\hline Sazonalidade(T_N, 1)Set & 32,6288 & 0,6351 & 51,38 & $<2 \mathrm{e}-16 * * *$ \\
\hline Sazonalidade( $\left.\mathrm{T}^{-} \mathrm{N}, 1\right)$ Out & 32,7741 & 0,6184 & 53 & $<2 \mathrm{e}-16 * * *$ \\
\hline Sazonalidade(T_N, 1)Nov & 32,9644 & 0,6136 & 53,72 & $<2 \mathrm{e}-16 * * *$ \\
\hline Sazonalidade(T_N, 1)Dez & 32,9986 & 0,6147 & 53,69 & $<2 \mathrm{e}-16 * * *$ \\
\hline L(Precipitação_ $\bar{N}, 1)$ & $-0,0014$ & 0,0002 & $-6,48$ & $2,29 \mathrm{e}-10 * * *$ \\
\hline L(Umidade Relativa N, 0) & $-0,0243$ & 0,0079 & $-3,07$ & $0,00224 * *$ \\
\hline L(Vel. do vento_N, 1$)$ & $-0,1581$ & 0,0362 & $-4,37$ & $1,54 \mathrm{e}-05 * * *$ \\
\hline \multicolumn{5}{|l|}{ João Pessoa (JP)/PB(b) } \\
\hline Tendência(T_JP) & 0,040 & 0,002 & 18,58 & $<2 \mathrm{e}-16 * * *$ \\
\hline Sazonalidade(T_JP, 1)Jan & 34,490 & 0,638 & 54,05 & $<2 \mathrm{e}-16 * * *$ \\
\hline Sazonalidade(T_JP, 1)Fev & 34,697 & 0,637 & 54,48 & $<2 \mathrm{e}-16 * * *$ \\
\hline
\end{tabular}

Gomes, A. C. S; Coutinho M. D. L; Viana, F. P.; Branches, L.; Tavares, S. F. S.; Alfaia, V. M.; Mendes, A. V. P.; Silva, S.; Sousa, E. L.R.; Mandú, T. B. 
Revista Brasileira de Geografia Física v.14, n.04 (2021) 2427-2445.

\begin{tabular}{|c|c|c|c|c|}
\hline \\
\hline Sazonalidade(T JP, 1)Mar & 34,909 & 0,636 & 54,85 & $<2 \mathrm{e}-16 * * *$ \\
\hline Sazonalidade(T_JP, 1)Abr & 34,632 & 0,643 & 53,89 & $<2 \mathrm{e}-16 * * *$ \\
\hline Sazonalidade(T JP, 1)Mai & 34,285 & 0,659 & 52,05 & $<2 \mathrm{e}-16 * * *$ \\
\hline Sazonalidade(T_JP, 1)Jun & 33,473 & 0,665 & 50,31 & $<2 \mathrm{e}-16 * * *$ \\
\hline Sazonalidade(T JP, 1)Jul & 32,843 & 0,669 & 49,09 & $<2 \mathrm{e}-16 * * *$ \\
\hline Sazonalidade(T_JP, 1)Ago & 32,768 & 0,659 & 49,73 & $<2 \mathrm{e}-16 * * *$ \\
\hline Sazonalidade(T_JP, 1)Set & 33,084 & 0,643 & 51,47 & $<2 \mathrm{e}-16 * * *$ \\
\hline Sazonalidade(T_JP, 1)Out & 33,610 & 0,634 & 53,02 & $<2 \mathrm{e}-16 * * *$ \\
\hline Sazonalidade(T $\left.{ }^{-} \mathrm{JP}, 1\right) \mathrm{Nov}$ & 34,088 & 0,635 & 53,68 & $<2 \mathrm{e}-16 * * *$ \\
\hline Sazonalidade(T_JP, 1)Dez & 34,355 & 0,637 & 53,95 & $<2 \mathrm{e}-16 * * *$ \\
\hline L(Precipitação_JP, 0) & $-0,001$ & 0,000 & $-4,76$ & $2,58 \mathrm{e}-06 * * *$ \\
\hline L(Umidade relativa_JP, 0) & $-0,053$ & 0,009 & $-6,16$ & $1,56 \mathrm{e}-09 * * *$ \\
\hline L(Vel. do vento_JP, 1) & $-0,199$ & 0,048 & $-4,12$ & $4,57 \mathrm{e}-05 * * *$ \\
\hline \multicolumn{5}{|l|}{ Recife (R)/PE(c) } \\
\hline Tendência(T_R) & 0,028 & 0,003 & 8,6 & $<2 \mathrm{e}-16 * * *$ \\
\hline Sazonalidade(T_R, 2)Fev & 32,267 & 0,622 & 51,85 & $<2 \mathrm{e}-16 * * *$ \\
\hline Sazonalidade(T_R, 2)Jan & 32,054 & 0,614 & 52,24 & $<2 \mathrm{e}-16 * * *$ \\
\hline Sazonalidade( $\left.\mathrm{T}^{-} \mathrm{R}, 2\right) \mathrm{Mar}$ & 32,491 & 0,627 & 51,79 & $<2 \mathrm{e}-16 * * *$ \\
\hline Sazonalidade(T_R, 2)Abr & 32,094 & 0,639 & 50,21 & $<2 \mathrm{e}-16 * * *$ \\
\hline Sazonalidade(T_R, 2)Mai & 31,495 & 0,658 & 47,86 & $<2 \mathrm{e}-16 * * *$ \\
\hline Sazonalidade(T_R, 2)Jun & 30,628 & 0,677 & 45,23 & $<2 \mathrm{e}-16 * * *$ \\
\hline Sazonalidade( $\left.\mathrm{T}^{-} \mathrm{R}, 2\right) \mathrm{Jul}$ & 29,959 & 0,683 & 43,85 & $<2 \mathrm{e}-16 * * *$ \\
\hline Sazonalidade( $\left.\mathrm{T}_{-} \mathrm{R}, 2\right)$ Ago & 29,777 & 0,675 & 44,11 & $<2 \mathrm{e}-16 * * *$ \\
\hline Sazonalidade(T_R, 2)Set & 30,166 & 0,653 & 46,2 & $<2 \mathrm{e}-16 * * *$ \\
\hline Sazonalidade(T_R, 2)Out & 30,954 & 0,631 & 49,06 & $<2 \mathrm{e}-16 * * *$ \\
\hline Sazonalidade(T_R, 2)Nov & 31,603 & 0,612 & 51,65 & $<2 \mathrm{e}-16 * * *$ \\
\hline Sazonalidade( $\left.\mathrm{T}_{-} \mathrm{R}, \mathrm{2}\right) \mathrm{Dez}$ & 31,971 & 0,607 & 52,66 & $<2 \mathrm{e}-16 * * *$ \\
\hline L(Precipitação_R, 0) & $-0,002$ & 0,000 & $-9,92$ & $<2 \mathrm{e}-16 * * *$ \\
\hline L(Umidade relativa_ $\mathrm{R}, 1$ ) & $-0,026$ & 0,007 & $-3,5$ & $0,000505 * * *$ \\
\hline L(Vel. do vento_R, 4) & 0,054 & 0,053 & 1,01 & $\mathbf{0 , 3 1}$ \\
\hline
\end{tabular}

Na Tabela 5, observa-se o MRD para Maceió/AL, Aracaju/SE e Salvador/BA possui ajustes semelhantes, com significância estatística na tendência, sazonalidade no lag 1 e todas as várias testadas, destaca-se lag $O$ (sem defasagem) para a precipitação em Maceió, lag 0 para Umidade relativa do ar em Aracajú e lag-1 na velocidade do vento em Salvador. Todos os três modelos apresentaram $\mathrm{R}^{2}=0,99$ (valor-p<0,001). Acreditase que as diferenças nas defasagens encontradas estão associadas a fatores externos a meteorológica.

Tabela 5. Coeficientes estimados do MRD para temperatura máxima do ar via variáveis meteorológicas em Maceió/AL(a), Aracaju/SE (b) e Salvador/BA (c).

\begin{tabular}{lcccc}
\hline Maceió (M)/AL(a) & & & & \\
& $\begin{array}{c}\text { Coeficientes } \\
\text { Estimados }\end{array}$ & Erro Padrão & Estatística T & Valor-p \\
Variáveis & 0,025 & 0,003 & 8,55 & $<2 \mathrm{e}-16 * * *$ \\
Tendência(T_M) & 32,684 & 0,904 & 36,17 & $<2 \mathrm{e}-16 * * *$ \\
Sazonalidade(T_M, 1)Jan & &
\end{tabular}


Revista Brasileira de Geografia Física v.14, n.04 (2021) 2427-2445.

\begin{tabular}{|c|c|c|c|c|}
\hline & & & & \\
\hline Sazonalidade(T_M, 1)Fev & 33,181 & 0,903 & 36,75 & $<2 \mathrm{e}-16 * * *$ \\
\hline Sazonalidade(T_M, 1)Mar & 33,242 & 0,885 & 37,57 & $<2 \mathrm{e}-16 * * *$ \\
\hline Sazonalidade(T_M, 1)Abr & 32,968 & 0,887 & 37,17 & $<2 \mathrm{e}-16 * * *$ \\
\hline Sazonalidade(T_M, 1)Mai & 32,567 & 0,874 & 37,28 & $<2 \mathrm{e}-16 * * *$ \\
\hline Sazonalidade(T_M, 1)Jun & 31,785 & 0,885 & 35,91 & $<2 \mathrm{e}-16 * * *$ \\
\hline Sazonalidade(T_M, 1)Jul & 30,893 & 0,905 & 34,13 & $<2 \mathrm{e}-16 * * *$ \\
\hline Sazonalidade(T_M, 1)Ago & 30,616 & 0,914 & 33,48 & $<2 \mathrm{e}-16 * * *$ \\
\hline Sazonalidade(T_M, 1)Set & 31,129 & 0,920 & 33,84 & $<2 \mathrm{e}-16 * * *$ \\
\hline Sazonalidade(T_M, 1)Out & 31,706 & 0,909 & 34,89 & $<2 \mathrm{e}-16 * * *$ \\
\hline Sazonalidade(T_M, 1)Nov & 32,559 & 0,916 & 35,56 & $<2 \mathrm{e}-16 * * *$ \\
\hline Sazonalidade(T_M, 1)Dez & 32,667 & 0,914 & 35,74 & $<2 \mathrm{e}-16 * * *$ \\
\hline L(Precipitação_M, 0) & $-0,004$ & 0,02 & $-11,74$ & $<2 \mathrm{e}-16 * * *$ \\
\hline L(Umidade Relativa_M, 1) & $-0,037$ & 0,010 & $-3,74$ & $0.000207 * * *$ \\
\hline L(Vel. do Vento_M, 1) & 0,200 & 0,094 & 2,12 & $0.034284 *$ \\
\hline Aracaju (A)/SE (b) & & & & \\
\hline Tendência(T_A) & 0,020 & 0,004 & 5,1 & $4,24 \mathrm{e}-07 * * *$ \\
\hline Sazonalidade(T_A, 1)Jan & 32,386 & 0,822 & 39,4 & $<2 \mathrm{e}-16 * * *$ \\
\hline Sazonalidade(T_A, 1)Fev & 31,970 & 0,845 & 37,8 & $<2 \mathrm{e}-16 * * *$ \\
\hline Sazonalidade(T_A, 1)Mar & 31,407 & 0,845 & 37,2 & $<2 \mathrm{e}-16 * * *$ \\
\hline Sazonalidade(T_A, 1)Abr & 30,674 & 0,854 & 35,9 & $<2 \mathrm{e}-16 * * *$ \\
\hline Sazonalidade(T_A, 1)Mai & 30,465 & 0,837 & 36,4 & $<2 \mathrm{e}-16 * * *$ \\
\hline Sazonalidade(T_A, 1)Jun & 30,569 & 0,828 & 36,9 & $<2 \mathrm{e}-16 * * *$ \\
\hline Sazonalidade(T_A, 1)Jul & 31,031 & 0,832 & 37,3 & $<2 \mathrm{e}-16 * * *$ \\
\hline Sazonalidade(T_A, 1)Ago & 31,555 & 0,830 & 38,0 & $<2 \mathrm{e}-16 * * *$ \\
\hline Sazonalidade(T_A, 1)Set & 31,867 & 0,825 & 38,6 & $<2 \mathrm{e}-16 * * *$ \\
\hline Sazonalidade(T_A, 1)Out & 32,267 & 0,815 & 39,6 & $<2 \mathrm{e}-16 * * *$ \\
\hline Sazonalidade(T_A, 1)Nov & 32,586 & 0,815 & 40,0 & $<2 \mathrm{e}-16 * * *$ \\
\hline Sazonalidade(T_A, 1)Dez & 32,735 & 0,816 & 40,1 & $<2 \mathrm{e}-16 * * *$ \\
\hline L(Precipitação_A, 1) & $-0,002$ & 0,004 & $-4,2$ & $3,61 \mathrm{e}-05 * * *$ \\
\hline L(Umidade Relativa_A, 0) & $-0,034$ & 0,010 & $-3,4$ & $0,000652 * * *$ \\
\hline L(Vel. do Vento_A, $\overline{1})$ & 0,089 & 0,045 & 2,0 & $0,046243 *$ \\
\hline Salvador (S)/BA (c) & & & & \\
\hline Tendência(T_S) & 0,04 & 0,004 & 9,34 & $<2 \mathrm{e}-16 * * *$ \\
\hline Sazonalidade(T_S, 1)Jan & 35,664 & 1,259 & 28,33 & $<2 \mathrm{e}-16 * * *$ \\
\hline Sazonalidade(T_S, 1)Fev & 35,643 & 1,242 & 28,71 & $<2 \mathrm{e}-16 * * *$ \\
\hline Sazonalidade(T_S, 1)Mar & 35,653 & 1,246 & 28,61 & $<2 \mathrm{e}-16 * * *$ \\
\hline Sazonalidade(T_S, 1)Abr & 34,534 & 1,252 & 27,59 & $<2 \mathrm{e}-16 * * *$ \\
\hline Sazonalidade(T_S, 1)Mai & 33,552 & 1,268 & 26,47 & $<2 \mathrm{e}-16 * * *$ \\
\hline Sazonalidade(T_S, 1)Jun & 32,757 & 1,291 & 25,37 & $<2 \mathrm{e}-16 * * *$ \\
\hline Sazonalidade(T_S, 1)Jul & 32,076 & 1,290 & 24,87 & $<2 \mathrm{e}-16 * * *$ \\
\hline Sazonalidade(T_S, 1)Ago & 32,058 & 1,284 & 24,96 & $<2 \mathrm{e}-16 * * *$ \\
\hline Sazonalidade(T_S, 1)Set & 32,865 & 1,284 & 25,6 & $<2 \mathrm{e}-16 * * *$ \\
\hline Sazonalidade(T_S, 1)Out & 33,996 & 1,272 & 26,72 & $<2 \mathrm{e}-16 * * *$ \\
\hline Sazonalidade(T_S, 1)Nov & 34,467 & 1,260 & 27,36 & $<2 \mathrm{e}-16 * * *$ \\
\hline Sazonalidade(T_S, 1)Dez & 35,166 & 1,265 & 27,8 & $<2 \mathrm{e}-16 * * *$ \\
\hline L(Precipitação_S, 1) & $-0,001$ & 0,005 & $-2,71$ & $0,00706 * *$ \\
\hline L(Umidade Relativa_S, 1) & $-0,073$ & 0,016 & $-4,7$ & $3,43 \mathrm{e}-06 * * *$ \\
\hline L(Vel. do Vento_S, -1) & 0,180 & 0,093 & 1,92 & 0,05496 \\
\hline
\end{tabular}


Revista Brasileira de Geografia Física v.14, n.04 (2021) 2427-2445.

\section{Construções de Cenários Futuros}

Elaboramos três diferentes cenários conforme mostra as Figuras 5, 6 e 7. Os Cenários foram nomeados de acordo com os períodos: 2020-2040 (C1), 2041-2060(C2) e 2061-2080 (C3). Verificase na Figura 5, que São Luís e Fortaleza apresenta em ambos os cenários, uma inclinação positiva mais acentuada do que em Teresina, no entanto nota-se que em Teresina os valores das temperaturas são mais elevados quando comparados os diferentes cenários. Em São Luís no $\mathrm{C} 1$, os valores estão em torno dos $35^{\circ} \mathrm{C}$. Já em Teresina acima desse valor e em Fortaleza abaixo desse valor. Com relação ao C2, Teresina apresenta valores a partir de $37,5^{\circ} \mathrm{C}$ e nas outras capitais a temperatura fica abaixo deste valor. No C3, destaca-se novamente Teresina por apresentar maiores valores. Segundo Marengo (2007) alguns cenários de alterações climáticas são acentuados devido Eventos El Niño-Oscilação Sul (ENSO) mais intensos que geram secas para a região do NEB. As grandes cidades se caracterizam pela geração de calor e a sua cobertura por construções diminui a percolação de água de chuva, e aumenta o fluxo ascendente de ventos, o que as torna vulneráveis para efeitos de aquecimento e enchentes (Barcellos et al., 2009).

Segundo o Relatório Especial do Painel Intergovernamental de Mudanças Climáticas (IPCC, 2018), as atividades humanas foram responsáveis por um aumento de aproximadamente $1{ }^{\circ} \mathrm{C}$ na atual temperatura média do planeta, comparada aos anos pré-industriais, e ainda é estimado temperaturas ainda mais altas após 2030. Isso pode parecer irrelevante diante das dimensões do planeta, mas a pandemia ocasionada pela Covid19 evidencia que existe relação entre a temperatura do ar e a disseminação de vírus, ou seja, o aumento de apenas $1^{\circ} \mathrm{C}$ pode fazer grande diferença. Afinal, a febre, como sintoma dessa pequena diferença de temperatura corporal, já é suficiente para indicar que o indivíduo carrega uma possível infecção viral (Duarte et al., 2020).

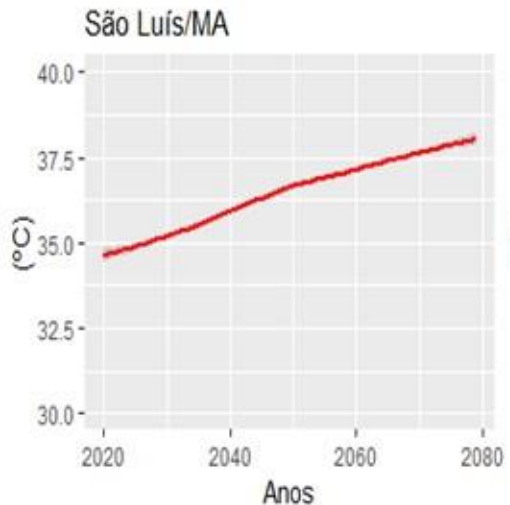

Cenários

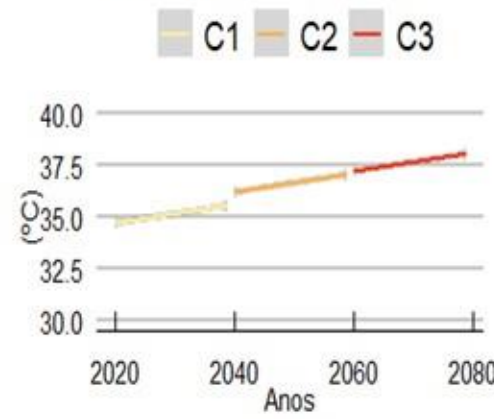

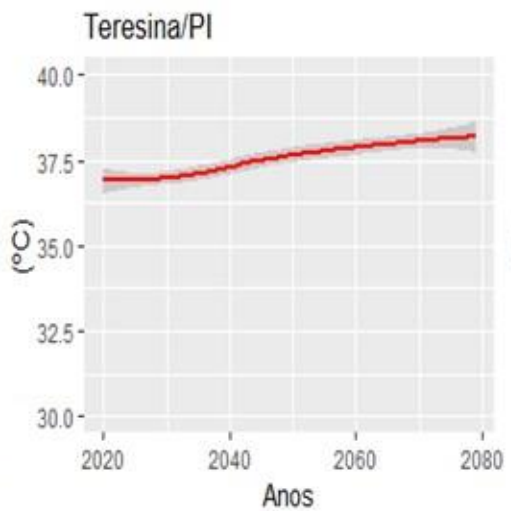

Cenários

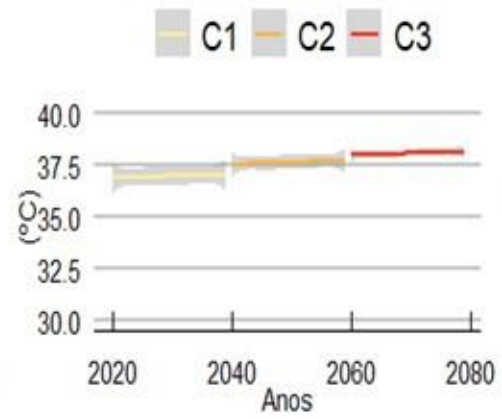

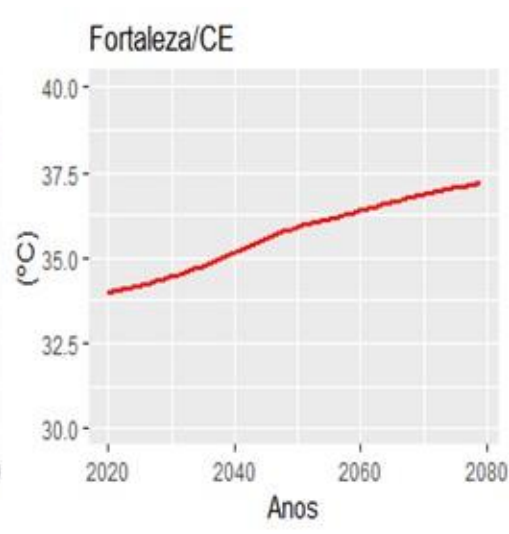

Cenários
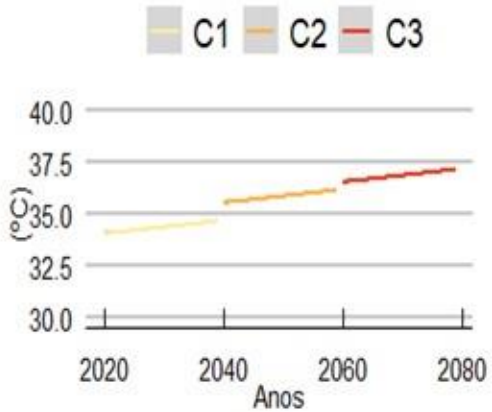

Figura 5. Cenários futuros para São Luís/MA, Teresina/PI e Fortaleza/CE nos períodos de 2020-2040 (C1), 2041-2060(C2) e 2061-2080 (C3). 
Revista Brasileira de Geografia Física v.14, n.04 (2021) 2427-2445.

Analisando a Figura 6, a temperatura apresenta valores inferiores aos das capitais mencionadas anteriormente. No $\mathrm{C} 1$ para Natal e Recife, nota-se valores na faixa dos $32,5^{\circ} \mathrm{C}$, sendo este cenário aproximadamente $1{ }^{\circ} \mathrm{C}$ mais elevado em João Pessoa.

Nos cenários C2 e o C3 em João Pessoa, têm-se maiores valores que as demais capitais, com temperatura chegando no $\mathrm{C} 3$ próximo de $37{ }^{\circ} \mathrm{C}$ referente ao período de 2070 a 2080. As mudanças climáticas podem produzir impactos sobre a saúde humana por diferentes vias (WHO, 2008), por um lado, impacta de forma direta, como as ondas de calor. Mas, esse impacto pode ser indireto, sendo mediado por alterações no ambiente como a alteração de ecossistemas e de ciclos biogeoquímicos, que podem aumentar a incidência de doenças infecciosas e doenças nãotransmissíveis, que incluem a desnutrição e doenças mentais (Barcellos et al., 2009; Gomes et al., 2013).

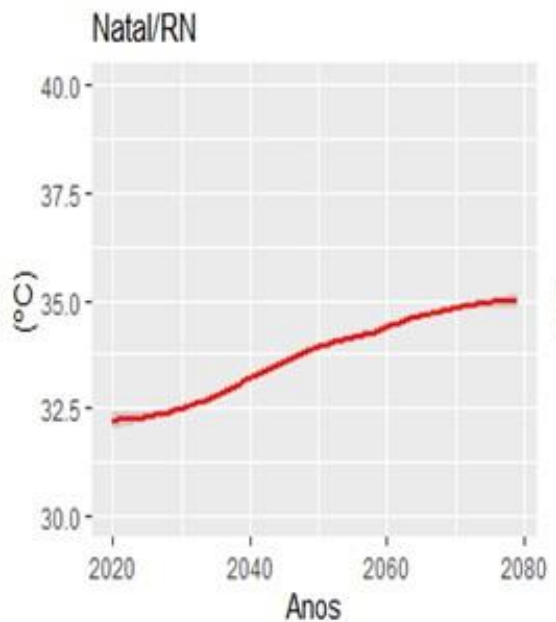

\section{Cenários}
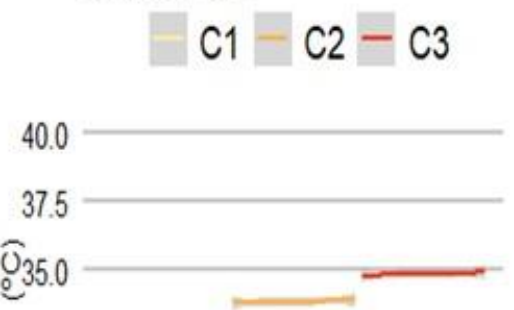

32.5

30.0

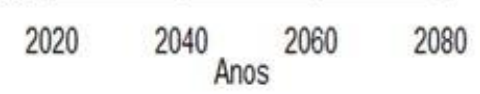

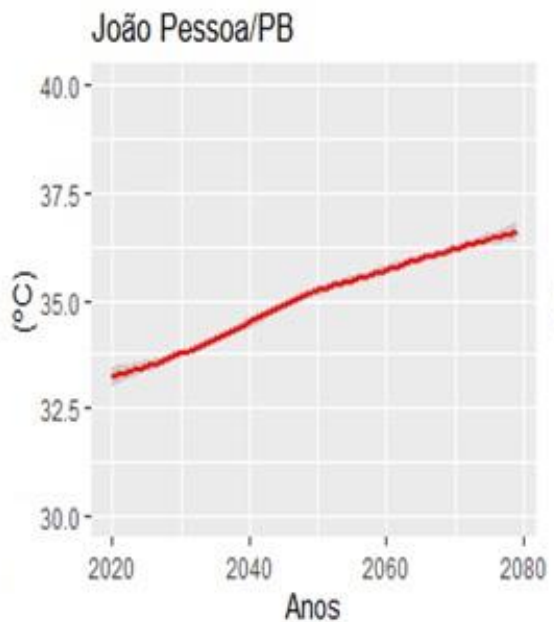

Cenários
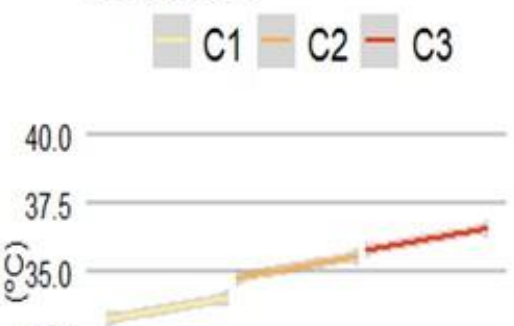

32.5

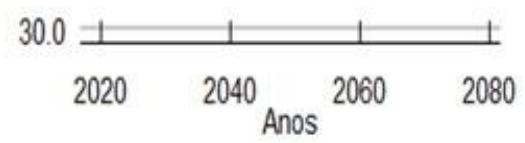

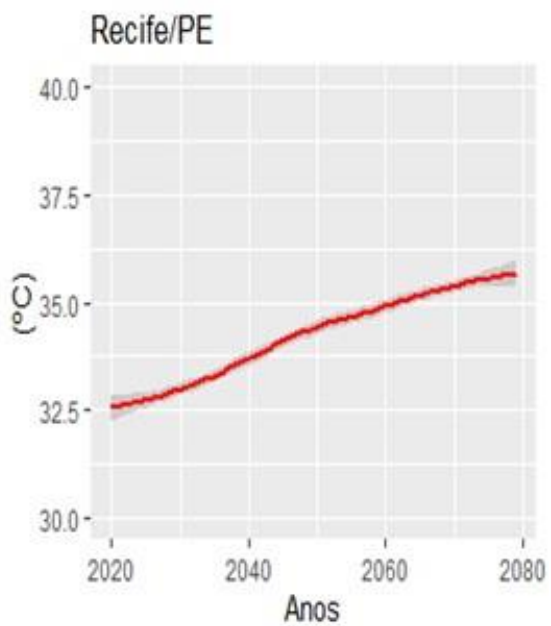

Cenários
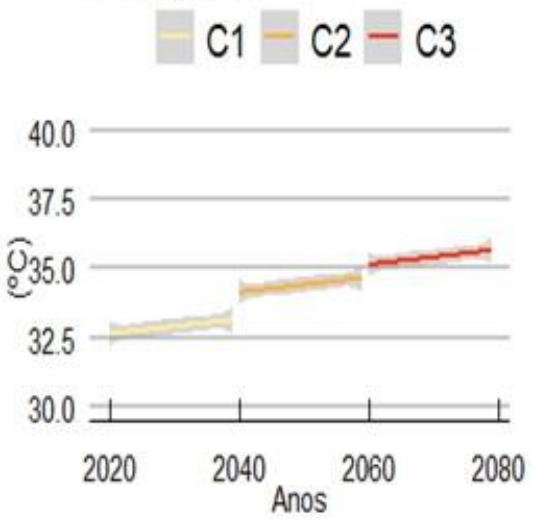

Figura 6. Cenários futuros para Natal/RN, João Pessoa/PB e Recife/PE nos períodos de 2020-2040 (C1), 20412060(C2) e 2061-2080 (C3).

A Figura 7 nos mostra as capitais com os valores menos elevados das capitais do NEB. Analisando inicialmente o $\mathrm{C}$, observa-se que nas capitais em Maceió, Aracaju e Salvador os valores das temperaturas estão na faixa dos $32,5{ }^{\circ} \mathrm{C}$. A inclinação positiva ocorre, mas não ultrapassa dos $36^{\circ} \mathrm{C}$. 
Revista Brasileira de Geografia Física v.14, n.04 (2021) 2427-2445.

Evidência que os resultados aqui encontrados já no cenário otimista são preocupantes, tendo em vista que muitos resultados encontrados em diferentes regiões do mundo mostram uma associação entre o aumento das temperaturas diárias e o aumento do número de mortes, doenças, e números de hospitalizações (Vutcovici, Goldberg e Valois, 2007).

De acordo com Nicholls et al., (2008), em situações nas quais a temperatura média diária excede $30^{\circ} \mathrm{C}$, há um incremento na taxa de mortalidade de pessoas acima de 65 anos de $15 \%$ a $17 \%$. Índices de mortalidade semelhantes também ocorrem quando as temperaturas mínimas diárias excedem $24^{\circ} \mathrm{C}$. Adicionalmente, são também evidenciados $\mathrm{o}$ aumento no número de hospitalizações e a demanda por serviços médicos durante períodos de calor excessivo (Anderson, Bell e Peng, 2013).

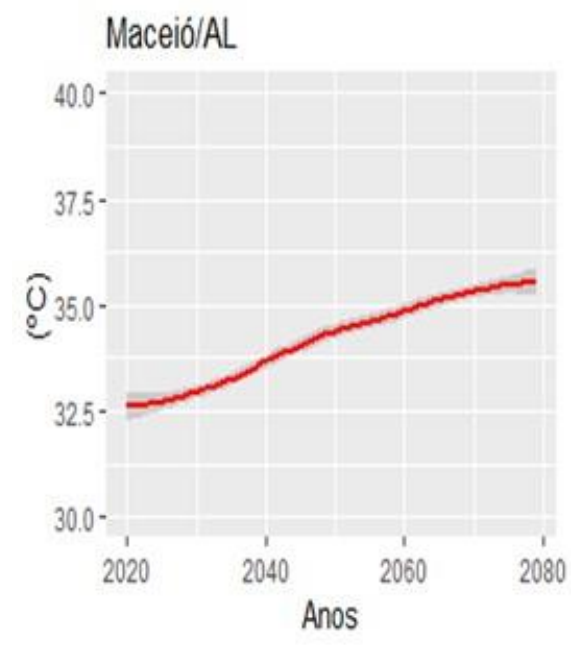

Cenários
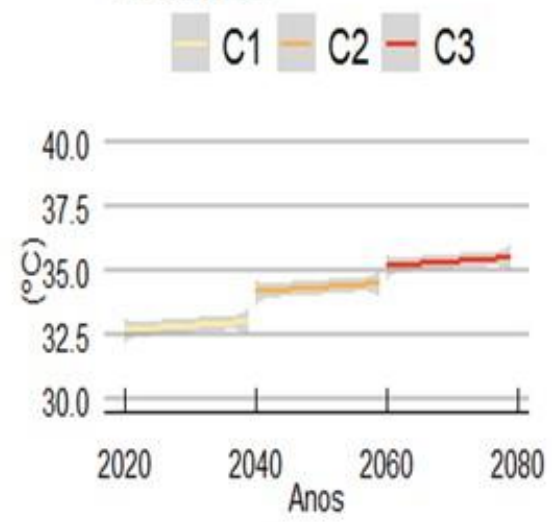

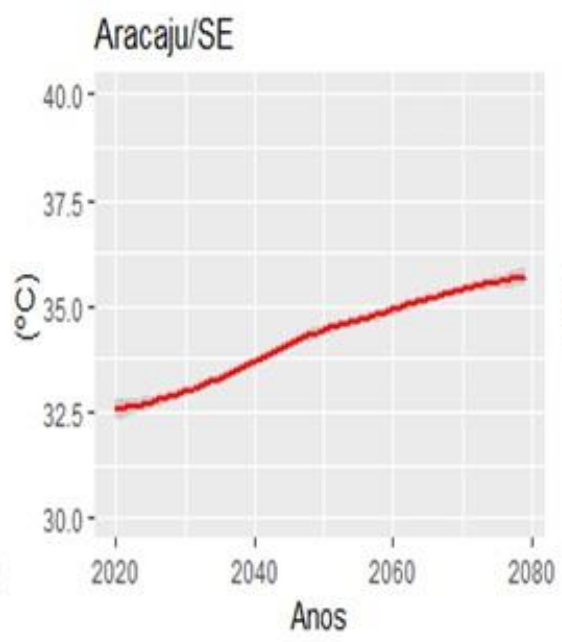

Cenários
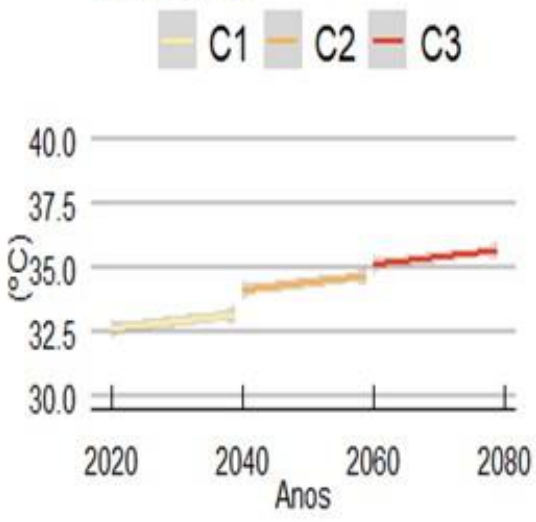

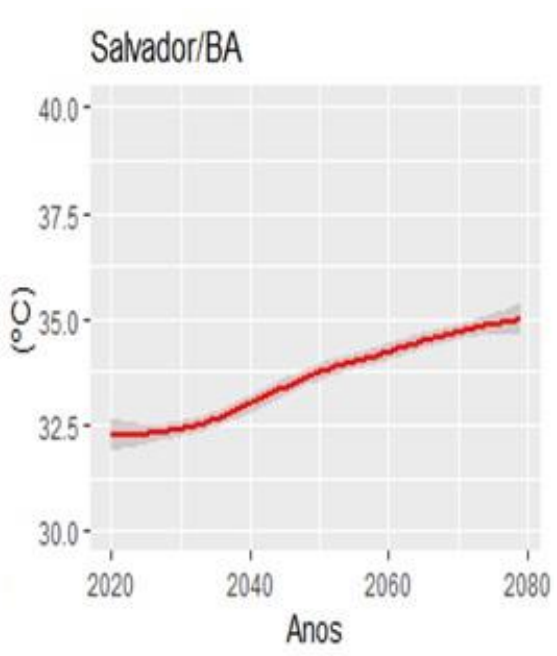

Cenários
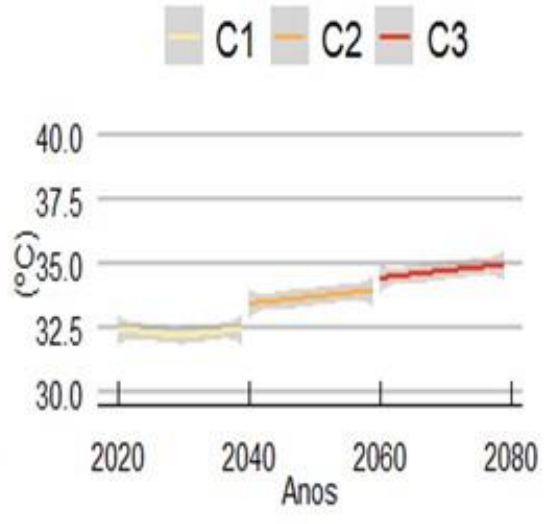

Figura 7. Cenários futuros para Maceió/AL, Aracaju/SE e Salvador/BA nos períodos de 2020-2040 (C1), 20412060(C2) e 2061-2080 (C3).

Os Cenários visualizados podem também contribuir para o declínio da produção agrícola na região, afetando a segurança alimentar da população rural, o que corrobora os resultados encontrados por Vieira et al., (2020). E mesmo o cenário otimista dificulta a capacidade adaptativa da população mais vulnerável (Cattaneo et al., 21019). Estudos como Cunha et al., (2019); da Rocha Júnior et al., (2019); da Rocha Júnior et al., (2020) ressaltam que áreas susceptíveis a adversidades climáticas, como a região Nordeste do Brasil, podem sofrer as consequências mais 
Revista Brasileira de Geografia Física v.14, n.04 (2021) 2427-2445.

graves destas mudanças, com secas mais intensas, a exemplo do último evento registrado de 2012 a 2018, devendo ocorrer com tempo de retorno cada vez menor.

É importante mencionar que Nóbrega et al., (2015), Guimarães et al., (2016) e Costa et al., (2020) mostram que existe uma tendência positiva das temperaturas no NEB, sugerindo também que cenários extremos irão ocorrer, no entanto, ressalta-se os resultados encontrados em estudos que envolvem mudanças climáticas sempre envolve muitas incertezas, devido a dinâmica da atmosfera e de variáveis e acontecimentos externos precisam ser sempre reavaliados e aprimorados.

\section{Conclusões}

Conclui-se que a modelagem estocástica via regressão dinâmica consegue estimar de forma satisfatória cenários futuros da temperatura máxima do ar nas capitais da região do nordeste brasileiro. No que diz respeito aos cenários, o $\mathrm{C} 1$ (otimista) apresentou temperaturas entre 32,5 e 35 ${ }^{\circ} \mathrm{C}$, o $\mathrm{C} 2$ (pessimista) entre 36 e $37,5^{\circ} \mathrm{C}$ e o $\mathrm{C} 3$ classificado como extremo e considerado mais alarmante alcançou os $39{ }^{\circ} \mathrm{C}$, valores perigosos para manutenção da qualidade de vida da população nordestina. Ressalta-se que estes são valores mensais, podendo ser mais alarmantes quando se analisa valores diários.

Teresina/PI foi a capital que apresentou as temperaturas máximas do ar mais elevadas e Salvador/BA a menos elevadas.

Por fim, é importante mencionar que a pandemia ocasionada pela Covid-19 causou enormes danos sociais e econômicos, o fato de que as mudanças do clima podem acelerar a transmissão de patógenos da vida selvagem aos humanos deve ser um alerta urgente para reduzir as emissões globais, além de motivar os governos aproveitem a oportunidade para reduzir os riscos à saúde de doenças infecciosas, tomando medidas decisivas para mitigar as mudanças climáticas.

\section{Agradecimentos}

Os autores agradecem ao Instituto de Engenharia e Geociências (IEG) da Universidade Federal do Oeste do Pará (UFOPA) e ao grupo de pesquisa Ciências Atmosféricas na Amazônia.

\section{Referências}

Anderson G. B, Bell M. L, Peng R. D. 2013. Methods to calculate the heat index as an exposure metric in environmental health research. Environ. health perspect., 121(10):1111-1119.

Andrade, K. M., 2005. Climatologia e comportamento dos sistemas frontais sobre a América do Sul. INPE-14056-TDI/1067. Dissertação (Mestrado em Meteorologia) INPE, São José dos Campos.

Barbieri, M. D., Ferreira, L. C., Barbi, F. Governando as mudanças climáticas. Ideias, 9(2), 71-98, 2018. doi:10.20396/ideias. v9i2.8655192

Barcellos C., Monteiro A. M. V., Corvalán C., Gurgel H. C., Carvalho M. S., Artaxo P. et al 2009. Mudanças climáticas e ambientais e as doenças infecciosas: cenários e incertezas para o Brasil. Epidemiol. Serv. Saúde.

Béné C. 2020. Resilience of local food systems and links to food security - a review of some important concepts in the context of COVID-19 and other shocks Food Secur., 12 (2020), pp. 805-822, 10.1007/s12571-020-01076-1

Beyer R.M., Manica A., Mora C., 2021. Shifts in global bat diversity suggest a possible role of climate change in the emergence of SARSCoV-1 and SARS-CoV-2, Science of the Total Environment, $\underline{\text { https://doi.org/10.1016/j.scitotenv.2021.14541 }}$ $\underline{3}$

Carvalho, M. G. F. Estado da Paraíba: classificação geomorfológica. 1982. João Pessoa, Ed. Universitária/Funape.

Cattaneo, C., Beine, M., Fröhlich, C., Kniveton, D., Martinez-Zarzoso, I., Mastrorillo, M. et al. 2019. Human Migration in the Era of Climate Change. Review of Environmental Economics and Policy, 13(2) 1-19.

Cavalcanti, I. F. A, Kousky, V. E., 2003. Climatology of South American cold fronts. In: VII International Conference on Southern Hemisphere Meteorology and Oceanography, AMS. Wellington, New Zealand.

Coutinho, E. C., Fisch, G. 2007. Distúrbios ondulatórios de leste (DOLs) na região do Centro de Lançamento de Alcântara-MA. Revista Brasileira de Meteorologia, 22, 193203. 
Revista Brasileira de Geografia Física v.14, n.04 (2021) 2427-2445.

Correa, M. J., Lima, K. C., Coutinho, M. D. L. 2019. Contribuição dos fluxos de umidade em evento de precipitação intensa ocorrido no leste do Nordeste do Brasil em maio de 2017: Um estudo de caso. Revista Brasileira de Geografia Física 12, 1703-1712.

Costa, R. L., Baptista, G. M. M., Gomes, H. B., Silva, F. D. S., Rocha Junior, R. L., Salvador, M. A., Herdies, D. L. Analysis of climate extremes indices over northeast Brazil from 1961 to 2014. Weather and Climate Extremes, 28, 100254, 2020.

Cunha, A. P. M. A., Zeri, M., Leal, K. D., Costa, L., Cuartas, L. A., Marengo, J. A., Tomasella, J., Vieira, R. M., Barbosa, A. A., Cunningham, C., Garcia, J. V. C., Broedel, E., Alvalá, R., Ribeiro-Neto, G. 2019. Extreme Drought Events over Brazil from 2011 to 2019. Atmosphere, 10, 642.

DA Rocha Júnior, R. L., Silva, F. D. S., Costa, R. L., Gomes, H. B., Herdies, D. L., Silva, V. P. R., Xavier, A. C. Analysis of the Space-Temporal Trends of Wet Conditions in the Different Rainy Seasons of Brazilian Northeast by Quantile Regression and Bootstrap Test. Geosciences, 9, 457, 2019.

DA Rocha Junior, R. L., Silva, F. D. S., Costa, R. L., Gomes, H. B., Pinto, D. D. C., Herdies, D. L. Bivariate Assessment of Drought Return Periods and Frequency in Brazilian Northeast Using Joint Distribution by Copula Method. Geosciences, 10, 135, 2020.

Ferreira, A. G. F., Mello, N. G. da S. 2005. Principais sistemas atmosféricos atuantes sobre a Região Nordeste do Brasil e a influência dos oceanos Pacífico e Atlântico no clima da região. Revista Brasileira de Climatologia, 1.

Gomes, A. C. dos S. et al. Clima e Doenças: Análise dos Elementos Meteorológicos e Infecções Respiratórias Agudas nas Capitais do Nordeste Brasileiro (Climate and Diseases: Analysis of Elements Meteorological and Respiratory Infections Acute in the Capitals of Northeast of Brazil). Revista Brasileira de Geografia Física, [S.1.], 6, 1069-1081, dez. 2013. ISSN 1984-2295. Disponível em: https://periodicos.ufpe.br/revistas/rbgfe/article/ view/233096>. Acesso em: 12 fev. 2021. doi: https://doi.org/10.26848/rbgf.v6i5.233096.

Guimarães, S. O, Costa, A. A, Junior, F. C. V. S. Silva, E. M, Sales, D.C, Junior, L. M. A, Souza,
S. G. Projeções de mudanças climáticas sobre o nordeste brasileiro dos modelos do CMIP5 e do CORDEX. Revista Brasileira de Meteorologia, 31, 337-365, 2016.

Hacon, S. S., Oliveira, B. F. A., Silveira, I. Climate Change Risks in Brazil: a review of the health sector impacts of $4^{\circ} \mathrm{C}$ or more temperature rise. Nobre, C. A., Marengo, J. A., Soares, W. R. (Org.). 2018. Impacts of $4{ }^{\circ} \mathrm{C}$ or more Temperature Risk. UK: Springer.

IBGE, Instituto Brasileiros de Geografia e Estatística. Disponível em: http://www.ibge.gov.br. Acesso em 01 jul. 2016.

IPCC. Climate Change 2013: The Physical Science Basis. Contribution of Working Group I to the Fifth Assessment Report of the Intergovernmental Panel on Climate Change [Stocker, T.F., D. Qin, G.-K. Plattner, M. Tignor, S.K. Allen, J. Boschung, A. Nauels, Y. Xia, V. Bex and P.M. Midgley (eds.)]. Cambridge University Press, Cambridge, United Kingdom and New York, NY, USA, $1535 \mathrm{p}$.

IPCC, 2018: Summary for Policymakers. In: Global Warming of $1.5^{\circ} \mathrm{C}$. An IPCC Special Report on the impacts of global warming of $1.5^{\circ} \mathrm{C}$ above pre-industrial levels and related global greenhouse gas emission pathways, in the context of strengthening the global response to the threat of climate change, sustainable development, and efforts to eradicate poverty [Masson-Delmotte, V., P. Zhai, H.-O. Pörtner, D. Roberts, J. Skea, P.R. Shukla,. Pirani, W.Moufouma-Okia, C. Péan, R. Pidcock, S. Connors, J.B.R. Matthews, Y. Chen, X. Zhou, M.I. Gomis, E. Lonnoy, T.Maycock, M. Tignor, and T. Waterfield (eds.)]. Disponível em: https://www.ipcc.ch/sr15/ Acesso em: 09 Dez. 2020

IPCC, 2019: Summary for Policymakers. In: IPCC Special Report on the Ocean and Cryosphere in a Changing Climate [H.-O. Pörtner, D.C. Roberts, V. Masson-Delmotte, P. Zhai, M. Tignor, E. Poloczanska, K. Mintenbeck, A. Alegría, M.Nicolai, A. Okem, J. Petzold, B. Rama, N.M. Weyer (eds.)]. Disponível em: https://www.ipcc.ch/srocc/ Acesso em: 03 fev. 20211

IPCC, 2020: Summary for policy makers Climate Change and Land. An IPCC Special Report on Climate Change, Desertification, Land 
Revista Brasileira de Geografia Física v.14, n.04 (2021) 2427-2445.

Degradation, Sustainable Land Management, Food Security, and Greenhouse Gas Fluxes in Terrestrial Ecosystems, Intergovernmental Panel on Climate Change, Geneva (2020). Disponível em: https://www.ipcc.ch/srocc/ Acesso em: 29 abr. 2021.

Kousky, V.E. 1979. Frontal Influences on Northeast Brazil. Monthly Weather Review. v107, 1140-1153.

Lacerda F. F., Nobre P., Sobral M. do C., Lopes G. M. B. 2015. Alterações climáticas globais: uma realidade em Pernambuco. Anais da Academia Pernambucana de Ciência Agronômica, Recife, $11 / 12,121-154$.

Marengo J. A. 2007. Mudanças climáticas globais e seus efeitos sobre a biodiversidade: caracterização do clima atual e definição das alterações climáticas para o território brasileiro ao longo do século XXI. Brasília: MMA.

Marengo, J. A. 2008. Vulnerabilidade, impactos e adaptação à mudança do clima no semiárido do Brasil. Parcerias estratégicas Brasília, DF, n.27 dezembro 2008.

Marengo A., Bernasconi, M. 2015. Regional differences inaridity/drought conditions over Northeast Brazil: Present state andfuture projections. Climatic Change, 129, 103-115. https://doi.org/10.1007/s10584-014-1310-1

Martins, M. A., Tomasella, J., Dias, C. G. 2019. Maize yield under achanging climate in the Brazilian northeast: Impacts and adaptation. Agricultural Water Management, 216, 339 350 .

https://doi.org/10.1016/j.agwat.2019.02.011

Nicholls N. L., Skinner C., Loughnan M., et al 2008. A simple heat alert system for Melbourne, Austrália. Int. J. Biometeorol., 52(5):375-384.

Nóbrega, R. S., Farias, R. F. L., Santos, C. A. C. Variabilidade temporal e espacial da precipitação pluviométrica em Pernambuco através de índices de extremos climáticos. Revista Brasileira de Meteorologia, 30, 171-180, 2015.

ONU. (2020). “Objetivo 13. Tomar medidas urgentes para combater a mudança climática e seus impactos". https://nacoesunidas.org/ pos2015/ods13/ abril.

PBMC, 2013. Contribuição do Grupo de Trabalho 2 ao Primeiro Relatório de Avaliação Nacional do Painel Brasileiro de Mudanças Climáticas. Sumário Executivo do GT2. PBMC, Rio de Janeiro, Brasil. 28 p. ISBN: 978-85-285-0208-4
PBMC 2014. Painel Brasileiro de Mudanças Climáticas. Base Científica das Mudanças Climáticas. Contribuição do Grupo de Trabalho 1 do Painel Brasileiro de Mudanças Climáticas ao Primeiro Relatório de Avaliação Nacional sobre Mudanças Climáticas. AMBRIZZI, T., ARAUJO, M. (eds). Coppe/Universidade Federal do Rio de Janeiro: Rio de janeiro, 464 p.

INMET. Instituto Nacional de Meteorologia Banco de Dados Meteorológicos para Ensino e Pesquisa. Disponível em: http://www.inmet.gov.br/projetos/rede/pesquis a/ Acesso: 20 de janeiro de 2015.

Pavani, B. F., Júnior, W. C. S., Inouye, C. E., Vieira, S. A., \& Mello, A. Y. (2018). Estimating and valuing the carbon release in scenarios of land-use and climate changes in a Brazilian coastal area. Journal of Environ-mental Manag. 226 , 416-

427.DOI: $10.1016 /$ j.jenvman.2018.08.059

Pavani, B. F., Júnior, W. C. S., Inouye, C. E., Vieira, S. A., Mello, A. Y. 2018. Estimating and valuing the carbon release in scenarios of landuse and climate changes in a Brazilian coastal area. Journal of Environ-mental Management, d climate changes in a Brazilian coastal area. Journal of Environ-mental Management, 226, 416-427.

https://doi.org/10.1016/j.jenvman.2018.08.059

Saddique, N., Bernhofer, C., Kronenberg, R., Usman, M. Downscaling of CMIP5 Models Output by Using Statistical Models in a Data Scarce Mountain Environment (Mangla Dam Watershed), Northern Pakistan. Asia-Pacific Journal of Atmospheric Sciences, v. 55, n. 1, 2019. https://doi.org/10.1007/s13143-01900111-2

Santos, A. P. P. D., Aragão, M. R. D. S., Correia, M. D. F., Santos, S. R. Q. D., Silva, F. D. D. S., Araújo, H. A. D. 2016. Precipitação na cidade de Salvador: variabilidade temporal e classificação em quantis. Revista Brasileira de Meteorologia, 31(4), 454-467.

Silva, K. Z., Colombo R. 2019. Mudanças Climáticas: influência antrópica, impactos e perspectivas. Fronteiras: Journal of Social, Technological and Environmental Science 8 (3), 47-68. https://doi.org/https:// doi.org/10. 21664/2238-8869. 2019v8i3.p47-68.

Tomasella, J., Vieira, R. M. S. P., Barbosa, A. A., Rodriguez, D. A., de Oliveira Santana, M., \& 
Revista Brasileira de Geografia Física v.14, n.04 (2021) 2427-2445.

Sestini, M. F. (2018). Desertification trends inthe northeast of Brazil over the period 20002016. International Jour-nal of Applied Earth Observation and Geoinformation, 73, 197206.https://doi.org/10.1016/j.jag.2018.06.012

UNDRR. Global Assessment Report on Disaster Risk Reduction. Geneva, Switzerland. United Nations Office for Disaster Risk Reduction (UNDRR). 2019. eISBN: 978-92-1-004180-5

Uvo, C. B., Berndtsson, R. 1996. Regionalization and spatial properties of Ceará State rain fall in Northeast Brazil. Journal of Geophysical Research, Washington, v. 101, p. 4221-4233.

Van B. S, Groothuis-Oudshoorn K. 2011. "mice: Multivariate Imputation by Chained Equations in R." Journal of Statistical Software,45(3), 167. https://www.jstatsoft.org/v45/i03/

Vieira R. M. da S. P., Sestini M. F, Tomasella J., Marchezini V., Pereira G. R., Barbosa A. A., Santos F. C., Rodriguez D. A., Nascimento F. R. do, Santana M. O., Campello F. C. B.,
Ometto J. P. H. B. 2020. Characterizing spatiotemporal patterns of social vulnerability to droughts, degradation and desertification in the Brazilian northeast,Environmental and Sustainability Indicators, Volume 5, 2020, 100016, ISSN 2665-9727, https://doi.org/10.1016/j.indic.2019.100016

Vieira, R. M. D., Tomasella, J., Barbosa, A. A., Martins, M. A., Rodriguez, D. A., Rezende, F. S., ... \& Santana, M. D. 2021. Desertification risk assessment in Northeast Brazil: Current trends and future scenarios. Land Degradation \& Development, 32(1), 224-240.

Vutcovici M., Goldberg M. S., Valois M. F. 2007. Effects of diurnal variations in temperature on nonaccidental mortality among the elderly population of Montreal, Quebec, 1984. Int J Biometeorol. 2014, 58(5):843-852.

Wang, C. 2002. Atlantic climate variability and its associated atmospheric circulation cells. Journal of Climate, 15, 1516-1536 
Revista Brasileira de Geografia Física v.14, n.04 (2021) 2427-2445.

Gomes, A. C. S; Coutinho M. D. L; Viana, F. P.; Branches, L.; Tavares, S. F. S.; Alfaia, V. M.; Mendes, A. V. P.; Silva, S.; Sousa, E. L.R.; Mandú, T. B. 